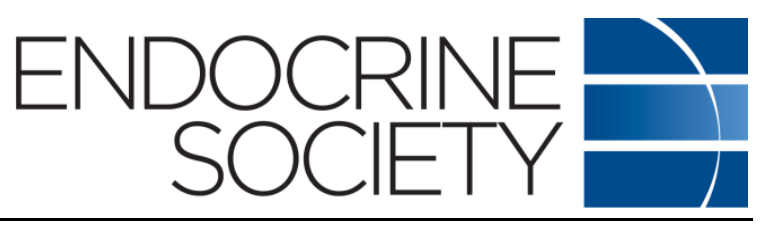

\title{
Transcription factor USF1 is required for maintenance of germline stem cells in male mice
}

Imrul Faisal, Sheyla Cisneros-Montalvo, Geert Hamer, Minna Tuominen, Pirkka-Pekka Laurila, Manuela Tumiati, Matti Jauhiainen, Noora Kotaja, Jorma Toppari, Juho-Antti Mäkelä, and Liisa Kauppi

\section{Endocrinology \\ Endocrine Society}

Submitted: December 21, 2018

Accepted: February 08, 2019

First Online: February 13, 2019

Advance Articles are PDF versions of manuscripts that have been peer reviewed and accepted but not yet copyedited. The manuscripts are published online as soon as possible after acceptance and before the copyedited, typeset articles are published. They are posted "as is" (i.e., as submitted by the authors at the modification stage), and do not reflect editorial changes. No corrections/changes to the PDF manuscripts are accepted. Accordingly, there likely will be differences between the Advance Article manuscripts and the final, typeset articles. The manuscripts remain listed on the Advance Article page until the final, typeset articles are posted. At that point, the manuscripts are removed from the Advance Article page.

DISCLAIMER: These manuscripts are provided "as is" without warranty of any kind, either express or particular purpose, or non-infringement. Changes will be made to these manuscripts before publication. Review and/or use or reliance on these materials is at the discretion and risk of the reader/user. In no event shall the Endocrine Society be liable for damages of any kind arising references to, products or publications do not imply endorsement of that product or publication. 
USF1 deficiency impairs male fertility

\section{Transcription factor USF1 is required for maintenance of germline stem cells in male mice}

Imrul Faisal ${ }^{1,2,3,4}$, Sheyla Cisneros-Montalvo ${ }^{5,6}$, Geert Hamer ${ }^{7}$, Minna Tuominen ${ }^{1}$, PirkkaPekka Laurila ${ }^{8,9,10}$, Manuela Tumiati ${ }^{1}$, Matti Jauhiainen ${ }^{11}$, Noora Kotaja ${ }^{5}$, Jorma Toppari 5,12 , Juho-Antti Mäkelä *\#5 and Liisa Kauppi *\#1,2

1. Genome-Scale Biology Research Program, Research Programs Unit, Faculty of Medicine, University of Helsinki, Helsinki, Finland

2. Department of Biochemistry and Developmental Biology, Faculty of Medicine, University of Helsinki, Helsinki, Finland

3. Doctoral Programme in Biomedicine (DPBM), Doctoral School in Health Sciences, Faculty of Medicine, University of Helsinki, Helsinki, Finland

4. Present address: Sunnybrook Health Sciences Center, 2075 Bayview Avenue, Faculty of Medicine, University of Toronto, Toronto M4N 3M5, ON, Canada

5. Institute of Biomedicine, Research Centre for Integrative Physiology and Pharmacology, University of Turku, Turku, Finland

6. Turku Doctoral Programme of Molecular Medicine (TuDMM), University of Turku, Turku, Finland

7. Center for Reproductive Medicine, Amsterdam Research Institute Reproduction and Development, Academic Medical Center, University of Amsterdam, Amsterdam, the Netherlands

8. Genomics and Biomarkers Unit, National Institute for Health and Welfare, Helsinki, Finland

9. Department of Medical and Clinical Genetics, University of Helsinki, Helsinki, Finland

10. Present address: École Polytechnique Fédérale de Lausanne, Lausanne, Switzerland

11. Minerva Foundation Institute for Medical Research and National Institute for Health and Welfare, Biomedicum, Helsinki, Finland

12. Department of Pediatrics, Turku University Hospital, Turku, Finland

ORCiD numbers:

0000-0001-6089-741X

Faisal

Imrul

0000-0002-6759-8997

Kauppi

Liisa

Received 21 December 2018. Accepted 08 February 2019.

A prerequisite for lifelong sperm production is that spermatogonial stem cells (SSCs) balance self-renewal and differentiation, yet factors required for this balance remain largely undefined. Using mouse genetics, we now demonstrate that the ubiquitously expressed transcription factor USF1 (Upstream stimulatory factor 1) is critical for the maintenance of SSCs. We show that USF1 is not only detected in Sertoli cells as previously reported, but also in SSCs. Usf1-deficient mice display progressive spermatogenic decline as a result of agedependent loss of SSCs. According to our data the germ cell defect in $U s f 1^{-/-}$mice cannot be 
attributed to impairment of Sertoli cell development, maturation or function, but instead is likely due to an inability of SSCs to maintain a quiescent state. SSCs of $U s f 1^{-/}$mice undergo continuous proliferation, which provides an explanation for their age-dependent depletion. The proliferation-coupled exhaustion of SSCs in turn results in progressive degeneration of the seminiferous epithelium, gradual decrease in sperm production and testicular atrophy. We conclude that the general transcription factor USF1 is indispensable for the proper maintenance of mammalian spermatogenesis.

\section{SIGNIFICANCE STATEMENT}

Upstream stimulatory factor 1 (USF1) is a ubiquitously expressed transcription factor which has been shown to regulate several important biological systems, such as lipid metabolism and insulin sensitivity. However, the role of USF1 in the regulatory pathways involved in stem cell biology has remained elusive. Using $U s f 1^{-/}$mice, we show that this protein is indispensable for proper maintenance of the spermatogonial stem cell pool. Our data suggest that USF1 is essential for the balance between self-renewal and differentiation of spermatogonial stem cells. In the absence of USF1, proliferation-coupled exhaustion leads to the gradual depletion of spermatogonial stem cells with age.

\section{INTRODUCTION}

During spermatogenesis, haploid spermatozoa are continually produced from diploid spermatogonia through several rounds of mitotic and two meiotic divisions. This complex process initiates from a population of undifferentiated germ cells, referred to as spermatogonial stem cells (SSCs). SSCs either self-renew or give rise to committed progenitors that are primed to differentiate under steady state. A balance between SSC selfrenewal and differentiation is critical for proper maintenance of spermatogenesis and for fertility [1]. Heretofore, mechanisms underlying SSC quiescence, as well as seminiferous cycle-dependent cell cycle entry and exit remain essentially undefined.

Spermatogenic cells are organized in the seminiferous epithelium in highly defined cell associations, or stages. In mouse, there are twelve stages (I-XII) that together constitute the cycle of the seminiferous epithelium. Proliferation of spermatogonia initiates from a population of isolated type $A$-single spermatogonia $\left(A_{s}\right)$. Cell division of $A_{s}$ first gives rise to a 2-cell cyst, i.e. A-paired $\left(\mathrm{A}_{\mathrm{pr}}\right)$, and then to A-aligned $\left(\mathrm{A}_{\mathrm{al}}\right)$ spermatogonia, typically consisting of 4,8 or 16 interconnected cells. Collectively these cells are referred to as Aundifferentiated spermatogonia, $\mathrm{A}_{\text {undiff. }}$ The $\mathrm{A}_{\text {undiff }}$ spermatogonia comprise of spermatogonial stem cells (SSCs) and transit-amplifying progenitor spermatogonia that are primed to differentiate but possess a latent self-renewal capacity [2-6]. $\mathrm{A}_{\text {undiff }}$ mitoses are not strictly bound to the progress of the seminiferous epithelial cycle but they are, however, restricted to stages X-II [7 8]. In contrast, their irreversible commitment towards meiosis is spatiotemporally strictly regulated and confined to stages VII-VIII of the seminiferous epithelial cycle [9]. At this point differentiating spermatogonia (A1) are formed that then undergo five additional mitotic divisions (A1-A2-A3-A4-In-B) before giving rise to preleptotene spermatocytes that enter meiosis.

Spermatogenesis is for a large part orchestrated by Sertoli cells that transduce endocrine signals (e.g. follicle-stimulating hormone $[\mathrm{FSH}]$ and testosterone) and other cellular cues into paracrine regulation of male germ cell differentiation [10]. Sertoli cells display unparalleled plasticity in terms of cellular function during the course of development and under steadystate spermatogenesis. Sertoli cell cyclical activity is a key to successful spermatogenesis; in addition to nursing up to five generations of differentiating germ cells, Sertoli cells also

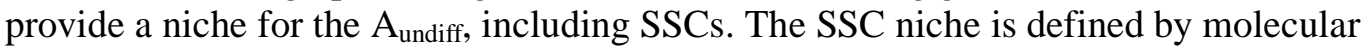


criteria. Glial cell line-derived neurotrophic factor (GDNF) is the most important single paracrine regulator of SSC fate. While Gdnf haploinsufficiency results in loss of SSCs, $\mathrm{A}_{\text {undiff }}$ accumulate if $G d n f$ is overexpressed [11 12 ]. In the testis, GDNF is derived from Sertoli, peritubular myoid and vascular endothelial cells, and its secretion is partially under endocrine regulation [11 13-18]. Besides GDNF, roughly a dozen other paracrine factors have been implicated in the regulation of SSC fate decisions [1 19].

Transcription factors, expressed by germ cells intrinsically and by somatic supporting cells, have also been implicated in the regulation and maintenance of spermatogenesis. PLZF [promyelocytic leukemia zinc finger; 20 21], TAF4B [TATA-box binding protein associated factor 4b; 22], SALL4 [Spalt-like transcription factor 4; 23 24] and FOXO1 [Forkhead box $\mathrm{O} 1 ; 25]$ are among germ cell intrinsic transcription factors whose function is essential for life-long spermatogenesis. Here, we dissect the requirement of Upstream stimulatory factor (USF) 1, a general transcription factor of the basic helix-loop-helix leucine zipper family, for mouse spermatogenesis. USF proteins are encoded by two ubiquitously expressed genes, Usf1 and Usf2, in mammals [26 27]. USF1-USF2 heterodimers bind the enhancer box (Ebox) in the promoter region of target genes [28 29]. In Sertoli cells of 5-11 days post partum (dpp) rats, USF proteins bind with increased affinity to Fshr (follicle-stimulating hormone receptor), Gata4, Nr5al (more commonly known as Sfl, steroidogenic factor-1), and Shbg (sex hormone-binding globulin) promoters, implying a role for USF in spermatogenesis [30].

As expected for a ubiquitously expressed transcription factor, USF1 has multifaceted roles in biological systems. In humans, USF1 polymorphisms are associated with regulating arterial blood pressure, synaptic plasticity in the central nervous system and lipid metabolism [31-34]. Recently, Laurila et. al. demonstrated that $U s f 1^{-/}$mice have beneficial lipid profiles, featuring reduced plasma triglycerides and elevated HDL-cholesterol, and are protected against diet-induced weight gain [35]. These findings indicate USF1 as a therapeutic target in cardio-metabolic diseases in humans. However, whether USF1 is dispensable for regulatory pathways involved in reproductive processes has remained elusive.

Very limited data exist on USF1 target genes in the testis. In silico predictions (UCSC genome browser and SABioscience's DECODE database, http://www.sabiosciences.com/) indicate that USF proteins in mammals regulate expression of thousands of genes, of which all USF2 target genes are also USF1 targets but not vice versa. In other words, there are many genes which are predicted to be regulated by USF1 only, which further highlights the importance of USF1 over USF2 in mammals. Using Usf1 knock-out (KO) mice [35], we now show that transcription factor USF1 is indispensable for proper maintenance of spermatogenesis, and more specifically, that USF1 is essential for maintaining a balance between self-renewal and differentiation of spermatogonial stem cells.

\section{MATERIALS AND METHODS}

Mice:

Knockout construct and generation of $U s f 1^{-/}$mice were as described previously [35]. Briefly, embryonic stem cells deficient for Usfl were obtained from German Genetrap Consortium (clone M121B03), in which, vector ROSAbetageo+2 was retrovirally delivered into the fourth exon of Usf1 gene. The resulting M121B03 cells were injected into C57BL/6J blastocysts in order to obtain Usfl heterozygous mice. These mice were further crossed to obtain Usfl knockout mice. All experiments in this study were performed following all applicable national and institutional guidelines (Animal Experiment Board in Finland and Laboratory Animal Centre of the University of Helsinki, respectively). The number of mice used in different experiments is detailed in Supplemental Table 1 [36].

\section{Genotyping:}


PCR primers and cycling conditions for genotyping Usfl were published previously [35]. See Supplementary Materials and Methods for details.

\section{Histological analysis:}

For basic histology testes were fixed with 4\% paraformaldehyde (PFA) in 1x PBS for four hours at room temperature, followed by Bouin's solution (Sigma, catalog no. HT10132) overnight. Testes were then dehydrated in $50 \%$ ethanol for four hours, $70 \%$ ethanol for four hours, and $70 \%$ ethanol for overnight, embedded in paraffin, and cut into 5- $\mu \mathrm{m}$ thick sections. Tissue sections were deparaffinized using standard xylene and alcohol series (absolute, 95\%, 90\%, and 70\% ethanol), and finally into sterile water. After staining with Mayer's hematoxylin solution (Sigma-Aldrich), sections were washed, counterstained with eosin (Sigma-Aldrich) and dehydrated using standard procedure (once with 70\%, 90\%, 95\%, and absolute ethanol, and twice with xylene), and mounted using a xylene-based mounting medium.

\section{Assessment of the spermatogenic defect:}

Testes were collected and fixed overnight in 4\% PFA followed by embedding into paraffin. Five-micrometer thick sections were prepared for histological analysis and stained with DAPI plus analyzed for integrity of the seminiferous epithelium. At least 64 cross-sections of seminiferous tubules per mouse (at the ages of 8, 12, 20 and 30 weeks; $n=2-3$ for WT, $n=3$ for $\mathrm{KO}$ ) from two non-consecutive histological sections were analyzed for the extent of spermatogenic defect and classified into three categories (normal, 1-3 layers missing, only basal layer) based on the presence or absence of hierarchical layers of differentiating germ cells.

\section{Immunofluorescent labeling on cryosections:}

Testes were dissected, fixed overnight in 4\% PFA followed by dehydration in $20 \%$ sucrose solution in 1x PBS, and embedding into OCT compound (Tissue-Tek). 10-micrometer thick sections were prepared for immunofluorescent labeling. Slides containing testis crosssections were washed briefly in PBS, and boiled in $10 \mathrm{mM}$ sodium citrate buffer (pH: 6.0) for 15-20 minutes in a microwave oven. Sections were then washed two times in PBS and blocked for one hour at room temperature in a blocking buffer containing 5\% BSA and 5\% normal serum (from same species in which secondary antibody was raised) in $0.2 \%$ PBST ( $0.2 \%$ tween-20 in $1 \mathrm{x}$ PBS). Primary antibody was diluted in antibody dilution buffer $(1 \%$ BSA in $0.2 \%$ PBST), incubated overnight in cold room and washed four times with $0.1 \%$ PBST next morning. Secondary antibodies were diluted in the same antibody dilution buffer as primary antibody and applied on the sections. Sections were incubated with secondary antibody solution for one hour at $37{ }^{\circ} \mathrm{C}$, washed four times with $0.1 \%$ PBST, mounted using Vectashield mounting medium containing DAPI (Vector Laboratories). Sections were imaged on a Zeiss Axioimager microscope, captured with ZEN2 software, and further processed with CorelDraw (version X7) image editing software. The following primary antibodies were used in this study: AR (RRID:AB_11156085), Claudin11 (RRID:AB_639330), GATA1 (RRID:AB_627663), GATA4 (RRID:AB_2108747), KI67 (RRID:AB_10854564), SOX9 (RRID:AB_2239761 and RRID:AB_2574463), WT1 (RRID:AB_2216233), PLZF (RRID:AB_2304760), USF1 (RRID:AB_2213986), GFR $\alpha 1$ (RRID:AB_2110307), Espin (RRID:AB_399174), and DNMT3A (RRID:AB_1149786) [37-49]. Antibody dilutions are provided at the Supplemental Table 2 [36].

\section{Immunofluorescent labeling on paraffin-embedded sections:}

Immunofluorescent labeling on 4\% PFA-fixed paraffin-embedded testis sections (see above) were used to analyze the total and proliferating number of Sertoli and Leydig cells at different timepoints (Supplemental Table 1). Double-labeling of cells with proliferation marker Ki67 antibody and cell type-specific antibodies (SOX9 for Sertoli cells, GATA4 for 
Leydig cells) was done. Briefly, slides were dewaxed using serial incubations in xylene and ethanol. Permeabilization was carried out in a pressure cooker in $0.1 \mathrm{M}$ citrate buffer $(\mathrm{pH}$ : 6.0) and autofluorescence was blocked with $100 \mathrm{mM} \mathrm{NH}_{4} \mathrm{Cl}$. Unspecific binding of the primary antibody was blocked by incubation in a buffer containing 5\% normal serum (from same species in which secondary antibody was raised $)$ in $0.05 \%$ TBST $(0.05 \%$ tween-20 in $1 \mathrm{x}$ TBS) for one hour. Primary antibodies were diluted in a blocking solution (5\% normal serum in $0.05 \%$ TBST) and incubated overnight in cold room. Secondary antibodies were diluted in the same blocking solution and applied on the sections for one hour at $37{ }^{\circ} \mathrm{C}$. DAPI was used as a nucleic counterstain. Finally the sections were mounted in Prolong ${ }^{\circledR}$ Diamond Antifade mountant (Thermo Fisher Scientific). Sections were imaged using The Pannoramic MIDI FL slidescanner with the 40x/Korr 0.95 Plan Apochromat objective (Zeiss).

\section{Isolation of stage-specific segments of seminiferous tubules:}

The testes of 8-week old $U s f 1^{--}(\mathrm{n}=3)$ and WT control $(\mathrm{n}=3)$ mice were dissected and decapsulated. Using transillumination-assisted microdissection method seminiferous tubule segments representing stages II-V, VII-VIII and IX-XI were dissected and snap-frozen in liquid nitrogen [50 51].

\section{RNA extraction and RT-qPCR:}

RNA was extracted from snap-frozen pieces of testicular tissue or staged segments of seminiferous tubule using Macherey-Nagel mini NucleoSpin RNA extraction kit (Catalog no. 740955.50) or TRIzol, respectively, (ThermoFisher Scientific) following manufacturers' protocol. $1 \mu \mathrm{g}$ of extracted RNA was reversed transcribed using either SuperScript VILO cDNA Synthesis Kit (ThermoFisher Scientific, Catalog no. 11754050) or SuperScript IV VILO Master Mix cDNA Synthesis kit (ThermoFisher Scientific, Catalog no. 11756050). RT-qPCR was performed using SsoAdvanced Universal SYBR Green Supermix (Bio-Rad, Catalog no. 1725270) and expression data was normalized to housekeeping genes. The list of primers used in this study is provided in Supplemental table 3 [36]. Data was analyzed using Bio-Rad CFX manager software (Version 3.1).

\section{Seminiferous tubules whole-mount staining:}

The preparation of seminiferous tubules for whole-mount stainings is described in Supplementary Materials and Methods. For immunostaining, seminiferous tubules were blocked for an hour using $0.3 \%$ PBSX (0.3\% Triton X-100 in 1x PBS) supplemented with $2 \% \mathrm{BSA}$ and $10 \%$ fetal bovine serum in a $2 \mathrm{ml}$ round-bottom tube on atating table at room temperature. Primary antibodies were diluted in $1 \%$ BSA in $0.3 \%$ PBSX and incubated overnight in cold room with rotation. Seminiferous tubules were then washed three times with $0.3 \%$ PBSX, incubated with secondary antibody diluted in $1 \%$ BSA in $0.3 \%$ PBSX for 2 hours on rotating table at room temperature and washed again three times. Finally, seminiferous tubules were arranged in linear strips, and mounted with Vectashield mounting medium containing DAPI (Vector Laboratories, Burlingame, CA). At least three WT and $U s f 1^{-/}$mice were used in the analyses.

\section{Sperm count:}

The number of cauda epididymal sperm was counted from 8 and 12-week old WT $(n=3)$ and $U s f 1^{-/}(\mathrm{n}=3)$ mice. For each mouse one cauda epididymis was dissected, few slits were made and placed in $1 \mathrm{~mL}$ PBS for approximately 30 minutes. The solution was pipetted up and down few times to homogenize and extract any remaining sperm. Sperm in $20 \mu \mathrm{l}$ homogenized PBS mixture of sperm were counted on a Bürker chamber (Marienfeld, Germany), and total sperm from $1 \mathrm{~mL}$ solution was calculated.

\section{Hormone measurements:}


For intratesticular hormonal level quantitation, testis lysates were prepared according to a protocol described earlier [52]. Briefly, testes were mechanically homogenized and lysed in APC buffer (20 mM Tris- $\mathrm{HCl}, \mathrm{pH} 7.7,100 \mathrm{mM} \mathrm{KCl,} 50 \mathrm{mM}$ sucrose, $0.1 \mathrm{mM} \mathrm{CaCl} 2,1 \mathrm{mM}$ $\mathrm{MgCl}_{2}$ ) supplemented with protease inhibitor (Cocktail set III, Merck Millipore, catalog no. 535140) at 1:200 dilution. The APC buffer was supplemented with 0.5\% Triton X-100 (final concentration) prior to lysate preparation. The lysed samples were centrifuged at $14000 \mathrm{xg}$ for 10-12 minutes at $4-8^{\circ} \mathrm{C}$. Pierce BCA kit (ThermoFisher Scientific) was used for measuring the lysate protein concentration. $20-\mu \mathrm{g}$ of total protein was used for each sample, and the hormone level quantitation was done according to manufacturer's instructions. Hormonal concentrations obtained from standard curve was further normalized to respective testis weights. For serum hormonal level quantitation, $25 \mu 1$ of serum were used for each reaction, and the concentrations were measured using standard curve made after manufacturer's instructions. Four mice per group were used for intratesticular hormonal measurement, whereas 5 mice per group were used for serum hormone level quantitation. The following ELISA kits were used: FSH ELISA kit (Novus Biologicals, catalog number KA2330), LH ELISA kit (Novus Biologicals, catalog number KA2332), and Testosterone ELISA kit (Abcam, catalog number ab108666).

\section{Statistics:}

Statistical tests were performed using GraphPadPrism software (Version 6). Unpaired $t$ tests were performed to calculate $p$ values; $p$ values $<0.05$ were considered statistically significant.

\section{RESULTS}

\section{USF1 expression within the seminiferous epithelium is detected in Sertoli cells and spermatogonia}

As a first step towards unraveling USF1's role(s) in spermatogenesis, we investigated which cells within the testis express USF1. Usf1 mRNA was detected at the whole-testis level at all the studied timepoints (Figure 1A). Moreover, its expression level in adult mice did not depend on the stage of the seminiferous epithelial cycle (Figure 1B). In adult wildtype mice, USF1 was detected in Sertoli cell nuclei by indirect immunofluorescence. In agreement with mRNA level data, USF1 protein expression was not affected by the stage of the seminiferous epithelial cycle (Figure 1C). To confirm that the USF1-positive cells are Sertoli cells, antibodies against two well-known Sertoli cell markers, GATA1 and WT1, were included in the staining protocol. USF1-positive seminiferous epithelial cells invariably also expressed WT1 but were GATA1-positive only in a subset of cross-sections (Figure 1C), as expected [53]. Interstitial cells also stained weakly for USF1. Reassuringly, Usf1 $1^{-/}$testes were negative for USF1, but exhibited normal expression of GATA1 and WT1 (Figure 1C).

Based on this localization pattern, testicular USF1 expression appeared to be restricted to testicular somatic cells, and missing from germ cells. Due to the extensive tissue handling procedure, it can be challenging to reveal low level of protein expression in paraffinembedded tissues sections. Therefore, we performed whole-mount staining of fixed seminiferous tubules, which allows three-dimensional visualization of the tissue and can provide more sensitive detection of low abundance proteins. Indeed, this approach confirmed the expression of USF1 in Sertoli cells, but also revealed USF1 expression in PLZF-positive cells, i.e. spermatogonia, on the basement membrane of the seminiferous epithelium (Figure 1D-E). PLZF, originally regarded a specific marker for undifferentiated stem and progenitor spermatogonia, has since been shown to be expressed also in early differentiating spermatogonia [21 54 55].

To further characterize the USF1-positive spermatogonial population we stained for DNMT3A, a protein whose expression is induced upon differentiation commitment in the male germline [56] and maintained in all populations of differentiating spermatogonia (A1- 
A4, In, B) and preleptotene spermatocytes. The highest level of USF1 was observed in PLZF+/DNMT3A- and PLZF+/DNMT3A+ cells, i.e. undifferentiated ( $\mathrm{A}_{\text {undiff }}$ ) and early differentiating spermatogonia (Supplementary Figure 1A). A more detailed analysis of USF1 expression within the differentiating spermatogonial population revealed that USF1 levels were sharply downregulated in differentiating spermatogonia (Supplementary Figure 1B). Since A1 differentiating spermatogonia are derived from $\mathrm{A}_{\text {undiff }}$ spermatogonia without mitosis in a retinoic acid-dependent transition [7], USF1 can be justifiably considered a novel marker for $\mathrm{A}_{\text {undiff }}$ spermatogonia.

$A_{\text {undiff }}$ spermatogonia are considered to consist of two populations of cells: actual stem cells (SSCs) that undergo self-renewal, and transit-amplifying progenitor cells [2-5]. $A_{\text {undiff }}$ expressing GFR $\alpha 1$ (GDNF family receptor alpha-1), most often representing $A_{s}$ and $A_{p r}$ cells, are more likely to act as stem cells, whereas differentiation-primed SOX3-positive $A_{\text {undiff, }}$, typically represent longer cysts [57]. Triple-staining of mouse seminiferous tubules with antibodies against GFR $\alpha 1$, USF1 and SOX9 confirmed that a subset of USF1-positive $A_{\text {undiff }}$ spermatogonia also express the stem cell marker GFR $\alpha 1$, which suggests that USF1 is also present in SSCs (Supplementary Figure 1B). A summary of the marker expression based on whole-mount IF stainings is provided in Figure $1 \mathrm{~F}$.

\section{Reduced testis weight in $\mathrm{UsfI}^{-/}$mice}

Body and testis weight of $U s f 1^{-/}$and control mice were recorded at multiple timepoints, from the first week post partum to 20 weeks. Decreased body weight and size in $U s f 1^{--}$mice was observed at all timepoints (Figure 2A, Supplementary Figure 2). Similar to body weight, testis size and weight were also smaller in knockout mice (Figure 2B-C). Further, relative testis weight was lower in $U s f 1^{-/}$mice at all the examined timepoints as compared to control mice, and it was significantly lower after birth and in adulthood from 12 weeks onward (Figure 2D). Thus, USF1 deficiency affects body weight and testis growth. Despite USF1deficient males' lower testis and body weight, these mice were otherwise healthy and able to sire offspring.

\section{$U s f 1^{-/}$mice display progressive degeneration of the seminiferous epithelium}

Testis histology of adult $U s f 1^{-/}$and wild-type control $\left(U s f 1^{+/+}\right)$mice was studied at $8,12,20$ and 30 weeks of age. The spermatogenic defect of $U s f 1^{-/-}$mice became obvious in 12-week old mice. While control mice hosted normal spermatogenesis in nearly all tubules, a substantial proportion of seminiferous tubules of $U s \mathrm{fl}^{-/}$mice had degenerated at that timepoint (Figure 2E-F). The magnitude of this defect increased with age, and in 30-week old knockout mice only a minority of tubules hosted spermatogenesis (Figure 2G). Moreover, seminiferous tubules with ongoing spermatogenesis typically appeared to contain a lower number of differentiating cells per cross-sectional area and displayed thus lower cellular density (Figure 2H-J). Closer examination revealed that many tubule cross-sections were devoid of specific types of germ cells.

A vast majority (92\%) of seminiferous tubule cross-sections in 8-week old $U s f 1^{-/}$mice still showed normal layering of the seminiferous epithelium consisting of 3-4 cohorts of differentiating germ cells. However, in older animals, cross-sections missing one, two or three layers of differentiating germ cells or containing only the basal layer became significantly more common (Figure $2 \mathrm{~K}-\mathrm{N}$ ). The cross-sections that lacked one to three layers of differentiating germ cells typically consisted of the basal layer plus elongating spermatids, potentially suggesting a spermiation defect. However, cross-sections lacking just one or two layers of spermatogenic cells were also identified (Supplementary Figure 3A-B). In line with the observations described above, epididymal sperm count in $U s f 1^{-/}$mice was only slightly decreased at 8 weeks of age but severely affected at the age of 12 weeks (Supplementary Figure 3C). 


\section{FSH, LH and testosterone levels are maintained in $U \boldsymbol{s} \boldsymbol{f} \mathbf{1}$-deficient mice}

The testis is an endocrine organ and pituitary-derived luteinizing hormone (LH) and follicle stimulating hormone (FSH) are essential for testicular development and function [58]. While serum testosterone level in $\mathrm{Usfl}^{-/}$mice was not different from wild-type controls, serum levels of LH and FSH were significantly higher (Figure 3A-C). These data indicate that the spermatogenic phenotype of $U s f 1^{-/}$mice is likely not due to insufficient gonadotropin stimulation. Interestingly, intratesticular testosterone (ITT) levels at 12 weeks' age in $U s f 1^{-1-}$ mice were significantly higher when compared to wild-type control mice (Figure 3D). This indicates that degeneration of seminiferous epithelium in $U s f 1^{-/-}$mice does not result from lack of androgen stimulation. To investigate whether high ITT in KO mice is due to Leydig cell hyperplasia, we quantified Leydig cells at different timepoints. However, no significant differences were observed (Figure 3E). Moreover, Leydig cell proliferation was not affected, and Leydig cells of both $U_{s f} 1^{-}$and wild-type mice entered mitotic quiescence by 12 weeks of age (Figure 3F). Transcript levels of LH receptor (Lhcgr) were also unaffected (Figure 3G). High ITT levels can at least in part be explained by the increased proportion of Leydig cells to other cell types in degenerating $U s f 1^{-/-}$testes.

Testosterone exerts its effect via binding to the androgen receptor (AR) that is expressed by Sertoli, Leydig and peritubular myoid cells in the testis. Cell type-specific AR action is essential for lifelong fertility, whereas global AR deficiency compromises masculinization [59-63]. Immunofluorescence detection indicated that AR expression in the testis between $U s f 1^{--}$and WT control mice does not differ (Figure $3 \mathrm{H}$ ). This was further corroborated by qPCR data showing normal $A R$ expression on the whole testis level (Figure 3I). Since correct stage-dependent gene expression is arguably essential for efficient progression of the spermatogenic program, we isolated tubules from three pooled epithelial stages (II-V, VIIVIII and IX-XI) for transcriptomic analyses using the seminiferous tubule transillumination method [50 51]. AR mRNA displayed the highest level of expression in early stages of the seminiferous epithelial cycle both in the knockout mice and WT controls (Figure 3J).

\section{Usf1-deficiency does not substantially affect Sertoli cell maturation and function}

Sperm production capacity is determined by the number of Sertoli cells, as a single Sertoli cell is able to host a specific number of germ cells in a species-dependent manner [64 65]. To address whether the low density of germ cells per cross-section of seminiferous epithelium in $U s f 1^{-1-}$ mice (Figure 2H-J) can be explained by a reduction in Sertoli cell number, we quantified Sertoli cells per tubular cross-section at different ages. However, no significant differences between KO and WT control mice were found (Supplementary Figure 4A).

During the first weeks of postnatal life, Sertoli cells undergo a maturation program that encompasses a shift in cell transcriptome/proteome, loss of mitotic activity and cell polarization. Because incomplete maturation of Sertoli cells might contribute to the spermatogenic phenotype observed in $U s f 1^{-/-}$mice, we investigated various aspects of the process. However, no significant differences between $U s f 1^{-/-}$and $U s f 1^{++}$Sertoli cells were recorded in mitotic activity (Supplementary Figure 4B), in expression of select Sertoli cell immaturity-related mRNAs [anti-Müllerian hormone (Amh), Podoplanin (Pdpn) and Cytokeratin-18 (Ck18) [66-68]] or in the localization of blood-testis barrier (BTB) proteins Claudin-11 and Espin (Supplementary Figure 5C-E). Collectively, these data led us to conclude that Sertoli cell maturation in $U s f 1^{-/-}$mice is not compromised.

Stage-dependent gene expression in Sertoli cells is somewhat deregulated in $U_{s} f I^{-/-}$mice USF1 is a transcriptional activator and it has been implicated in the regulation of two important testicular genes: FSH receptor (Fshr) [69-71] and Steroidogenic factor 1 (Sf1 or Nr5a1) [30 72]. In silico analyses further predict that there are USF1 binding sites upstream of a number of genes important for Sertoli cell function, including Gata4 [73 74] and Sox9 
[75]. RT-qPCR analysis did not reveal any statistically significant differences in the expression of these genes nor in another essential Sertoli cell transcription factor Wilm's tumor 1 [Wt1; 76 77] in Usf1 $1^{-/}$testes (Supplementary Figure 5A-D).

Sertoli cells undergo cyclical changes in their transcriptome as a result of the seminiferous epithelial cycle [78], and many genes expressed by Sertoli cells exhibit a variable level of expression, as dictated by the stage of the cycle. While all of the studied genes maintained their typical pattern of expression in different stages, elevated Gatal and Sox 9 mRNA levels, which are potentially biologically important, were observed at stages VII-VIII in KO mice (Figure 4).

Depletion of undifferentiated spermatogonia contributes to degeneration of the seminiferous epithelium in $U s f I^{--}$mice

In order to elucidate the origin of seminiferous epithelial degeneration in $U s f 1^{-/}$mice, we quantified the proportion of tubules that host PLZF-positive cells. It steadily decreased in Usfl KO mice with age (Figure 5A-B), indicating depletion of undifferentiated spermatogonia. Thus, the spermatogenic defect in these mice can at least partially be attributed to an inability of $U s f 1^{-/}$testes to maintain undifferentiated spermatogonia, i.e the stem and progenitor cells of the adult male germline.

\section{Stem cell niche in $U s f I^{-/}$mice}

Stem cells are located in a microenvironment that maintains their self-renewal capacity, i.e. the stem cell niche. In the mouse testis the niche cannot be defined by anatomical criteria but rather by molecular cues, and the fate of undifferentiated spermatogonia is dictated by the availability of a selection of paracrine factors. A number of factors have been implicated in the regulation of cell fate decisions within the mouse undifferentiated spermatogonia. While the role of Gdnf among these factors is best-characterized, Cxcl12 [79], Csf1 [80], Fgf2 [81], Nrgl [82] and Wnt4 [83], Wnt5a [79 84 85] and Wnt6 [86] are arguably also important regulators of $\mathrm{A}_{\text {undiff }}$ spermatogonia, whereas Bmp4 [87] and $S c f$ [88] become critical once the transition into A1 differentiating spermatogonia has taken place. We studied the mRNA expression of these genes at 1,4 , and 8 weeks. Despite considerable variation, no statistically significant changes for any of these genes were recorded, implying that the paracrine milieu that $\mathrm{A}_{\text {undiff }}$ spermatogonia are exposed to in the $U s f 1^{-/}$testis is not drastically different from that in the control testis (Supplementary Figure 6 and 7).

Because of the importance of GDNF and SCF for $\mathrm{A}_{\text {undiff }}$ and differentiating spermatogonia, respectively, we studied the expression of these two genes in staged tubules isolated from 8-week old mice. This timepoint was selected because in $U s f 1^{-1-}$ testis the first signs of seminiferous epithelial degeneration become apparent by then, but the cellularity still remains largely unaffected (Figure $2 \mathrm{~K}$ ). Consistent with data above (Figure 4), the stagespecific expression pattern for both $G d n f$ and $S c f$ was maintained in $U s f 1$ KO mice (Figure $5 \mathrm{C}-\mathrm{D})$. However, mRNA levels were generally higher in $U s f 1^{-/-}$mice, and the differences reached statistical significance at stages II-V for $G d n f$ and stages VII-VIII for $S c f$. These data indicate that spermatogonia in the $U s f 1^{-/-}$testis may be exposed to physiologically altered levels of paracrine growth factors at specific stages of the seminiferous epithelium, despite the fact that at the whole testis level no changes were recorded.

\section{A-single spermatogonia in $U s f 1^{-/-}$testes are hyperproliferative}

Increased apoptosis and proliferation-coupled stem cell exhaustion are amongst the obvious mechanisms that may contribute to the observed progressive depletion (Figure 5B) of germline stem cells within the $U s \mathrm{fl}^{-/}$testis. To investigate these options we employed indirect immunofluorescence on segments of seminiferous tubule from 8-week old WT and $U s f 1^{-1-}$ mice. As judged by cleaved caspase-3 staining, the incidence of apoptosis within the GFR $\alpha 1$-expressing $A_{\text {undiff }}$ was generally low irrespective of genotype, which is in line with 
earlier data [19] (Supplementary Figure 8). In contrast, GFR $\alpha 1$-positive $A_{\text {undiff }}$ spermatogonia were proliferatively active both in WT and $U s f 1^{--}$mice, as judged by proliferation marker Ki67 staining (Figure 6A-B). Interestingly, as illustrated in Figure 6B and Supplementary Figure 8, areas where GFR $\alpha 1$-positive cells were present at a very high density were occasionally encountered in the $U s f 1^{-1-}$ seminiferous tubules. This prompted us to study proliferation of GFR $\alpha 1$-expressing $A_{s}$ and $A_{\text {pr }}$ spermatogonial cells that are the main constituents of the stem cell pool under steady-state. While the majority of GFR $\alpha 1$-positive $\mathrm{A}_{\mathrm{s}}$ cells were Ki67-negative in the WT control testis, the situation was the opposite in the $U s f 1^{-/}$mice (Figure 6C-D). A similar trend was observed in GFR $\alpha 1$-positive $\mathrm{A}_{\mathrm{pr}}$ cells but this difference was not statistically significant. Based on these data, we conclude that proliferation-coupled exhaustion contributes to the depletion of stem cells in the Usf $I^{-/}$testis.

\section{DISCUSSION}

This study constitutes the first in vivo assessment of the role of USF1, a ubiquitously expressed transcription factor, in the maintenance of spermatogenesis. Loss of Usfl leads to age-related decline in sperm production, most likely due to depletion of spermatogonial stem cells. Even though young $U s f 1^{-/}$adult mice still hosted relatively normal spermatogenesis, the spermatogenic defect became obvious by 12 weeks of age and continued to exacerbate thereafter. This is a characteristic of stem cell maintenance failure, as has been previously demonstrated e.g. in Plzf [20 21], Taf4b [22] and Erm [89] deficient mice. Typically, some areas within the seminiferous tubules are able to maintain stem cells for a longer time, but the number of such areas, or niches that they contain, decreases with age, while tubules that contain only the basal layer of the seminiferous epithelium and are devoid of germ cells become more common. As an intermediate step, tubules that lack one to three layers of spermatogenic cells are observed. If stem cells are depleted, 35 days are needed by spermatogenesis to clear the tubule of germ cells. Notably, we also observed tubules which lacked spermatogenic cell layers at the end of differentiation hierarchy (i.e. spermatids) but retained the meiotic and mitotic populations. Similarly, tubule cross-sections missing any single layer were occasionally noted. This implies that in the $U s f 1^{-/}$testis not every cycle is able to give rise to differentiating progeny and that the stem cell compartment first functions less efficiently before it collapses.

The significance of mitotic quiescence in the long-term maintenance of stem cells is widely appreciated. Hence, the continued engagement of SSCs in the cell cycle provides an attractive explanation for the progressive spermatogenic failure in $U s f 1^{-/}$mice. Normally, $\mathrm{A}_{\text {undiff }}$ spermatogonia exit from the cell cycle at epithelial stage II and a subset of them becomes sensitive to retinoic acid as a result of differentiation-priming activity of Wnt signaling, and by upregulation of retinoic acid receptor gamma (RARg) [7 8690 91]. Expression of $R A R g$ and associated genes, including neurogenin-3 (Ngn3) and Sox3, thus delineate $A_{\text {undiff }}$ into differentiation-primed and stem subsets [4-6 57 90]. Interestingly, the mechanism(s) responsible for the $\mathrm{A}_{\text {undiff }}$ cell cycle exit are essentially undefined. Notably, however, Gdnf is expressed at the lowest level at stages VII-VIII, i.e. the same stages where the early phase of differentiation-inducing RA pulse is recorded [17 91-95]. Similarly, $A_{\text {undiff }}$ spermatogonia re-enter the cell cycle at stage $\mathrm{X}$ in synchrony with reactivation of $G d n f$ expression and a sharp decline in RA levels [91 95]. A Andiff mitotic activity thus seems to be intimately coupled with GDNF availability. We speculate that elevated levels of GDNF at stages II-VIII in $U s f 1^{-/}$mice may contribute to prolonged proliferation of GFR $\alpha 1$-positive SSCs and to the inability to induce formation of the progenitor subset [96]. This scenario would result in smaller cohorts of differentiating progeny and ultimately in fewer sperm, as recently suggested by Sharma and Braun [12]. Moreover, prolonged engagement in the cell cycle may eventually lead to proliferation-coupled exhaustion of GFR $\alpha 1$-expressing 
spermatogonia, thus providing an explanation for the stem cell depletion phenotype (Figure 7).

Gdnf is an FSH-regulated gene [14 1617 97]. Interestingly, plasma FSH levels in $U s f 1^{-/-}$ mouse were elevated which may contribute to increased Gdnf expression in stages II-V (IIVIII). The significance of this connection, however, is unclear; the role of FSH in Gdnf regulation under physiological conditions has been recently called into question [84]. We initially speculated that another major endocrine factor, testosterone, might be more important for the phenotype. Testosterone is crucial for spermatogenesis and its levels inside the testis are around one order of magnitude higher than in plasma. Once deemed indispensable, recent research has shown that high ITT is not essential for sperm production, and that spermatogenesis can be initiated and maintained at a testosterone concentration similar to what is measured in plasma [98]. Testosterone has also recently been implicated in regulation of the spermatogonial stem cell niche via GDNF and WNT5A [13 84]. It is therefore possible that the stage II-V specific elevated $G d n f$ levels are due to high ITT measured in $U s f 1^{--}$mice. These stages have previously been shown to display a high sensitivity to androgen action [99]. WNT5A is a developmental regulator of the spermatogonial stem cell pool, and its expression is downregulated by testosterone [84]. We did not, however, detect any changes in Wnt5a mRNA levels in $U s f 1^{-/-}$testis.

In summary, the paracrine milieu in $U s f 1^{-/}$testes was somewhat altered compared to WT testes. However, the changes were modest, and no consistent reduction in the expression of the studied paracrine factor-encoding genes was observed. Moreover, the levels of endocrine factors were at a sufficiently high level to maintain spermatogenesis in the $U s f I^{-/-}$testis. Sertoli cells in adult $U s f 1^{--}$mice had matured normally and exhibited all characteristic aspects of adult-type Sertoli cells. Although we cannot rule out a role for a defunct SSC niche in $U s f 1^{-/}$testis, it seems likely that the phenotype is mostly of spermatogonial origin, and that USF1 is needed for the maintenance of the spermatogonial stem cell pool in a cellautonomous fashion. We propose that in the $U s f 1^{-/}$testis spermatogonial stem cells become continually engaged in the cell cycle, resulting in their depletion with age. This manifest itself as an accumulation of tubules displaying poor spermatogenic differentiation, smaller cohorts of differentiating germ cells, and disrupted layering of the seminiferous epithelium, collectively resulting in age-related reduction in sperm production.

There are numerous different mechanisms how loss of USF1 may contribute to the loss of spermatogonial stem cells in a cell-autonomous fashion. Namely, among its many functions, USF1 has been implicated in the control of cellular proliferation. Not only have several tumor suppressor genes been recognized as direct USF1 targets [PTEN, APC, p53, e.g.; 100 101103] but USF1 also stabilizes p53 [104], opposes the action of Myc at the transcriptional level [105] and may contribute to cellular immortality by maintaining TERT (telomerase reverse transcriptase) expression [106]. Hence the effect of USF1 on cellular proliferation is considered growth-inhibitory. Although USF1 has been shown to fulfill many aspects of a classical tumor suppressor protein, a connection between USF1 deficiency and increased proliferation or tumor formation has not been demonstrated. To our knowledge, this is the first direct demonstration that loss of USF1 results in higher cellular proliferation in vivo. Paradoxically, however, increased stem cell proliferation does not result in tissue growth but rather in hypoplasia due to a stem cell maintenance defect. It remains to be thoroughly investigated if (partial) depletion of stem cells contributes to tissue growth defects in other tissues, besides the testis, in $U s f 1^{-/}$mice.

Deficiency of USF1 or USF2 can typically be compensated for by the formation of USF2 or USF1 homodimers, respectively [29 107]. In Usf1 $1^{-/}$testes, USF2 homodimers are expected to compensate for lack of USF1 at most USF-dependent gene promoters, as demonstrated by Hermann and co-workers for the Fshr gene in Sertoli cells [71]. In agreement with this study, 
we also found that Fshr expression was unaffected in the absence of USF1. Furthermore, loss of USF1 activity neither affected expression of genes involved in Sertoli cell maturation or function, nor had an overt impact on the stem cell niche. Thus, USF2 is likely sufficient to compensate for USF1 loss in paracrine and autocrine regulation by Sertoli cells. This, however, is likely not the case for the testicular stem cell pool. We speculate that there are USF1-regulated gene(s) in undifferentiated spermatogonia whose transcription cannot be maintained by USF2 homodimers, and that lack of their expression results in the gradual depletion of stem cells in a cell-autonomous fashion.

USF1 deficiency in mouse and reduced USF1 expression in humans has been shown to help maintain a beneficial lipid profile (i.e. higher high-density lipoprotein and lower triglycerides), insulin-sensitivity and to protect against hardening of the arteries. Therefore, targeting USF1 has excellent clinical potential in the treatment of obesity, diabetes, and cardiovascular diseases [35]. Here we have shown that loss of USF1 also has adverse effects on reproductive function, a finding that might intuitively raise doubts about appropriateness of USF1 as a drug target. However, Usfl heterozygous mice, that also displayed reduced weight gain and more beneficial lipid profiles [35], did not show spermatogenic defects. Thus, while complete absence of USF1 leads to impaired spermatogenesis, partial loss $\left(U s f 1^{+/-}\right.$mice) does not appear to have these effects. Thus, our present findings are still compatible with our previous proposal [35] of the potential of USF1 modulation as a therapeutic treatment strategy for cardiometabolic disease. We have uncovered a significant novel role for USF1 as a factor required for spermatogenesis, highlighting the varied physiological roles of this transcription factor.

\section{SUPPLEMENTAL INFORMATION:}

Supplementary materials and methods, tables and figures have been provided in an online repository, which is available at https://dx.doi.org/10.6084/m9.figshare.7670807 [36]

\section{ACKNOWLEDGEMENTS:}

We are grateful to Hannu Sariola, Jarkko Soronen, Juha Tapanainen, Taneli Raivio, Pekka Katajisto, and Timo Tuuri (University of Helsinki, Finland) for suggestions and advice on experimental procedures. We thank Elli Aska, Nanna Sarvilinna, Kul Shrestha and Barun Pradhan (Kauppi lab) for their assistance with experimental procedures. Assistance was also provided by the following core facilities at the University of Helsinki: the Tissue Preparation and Histology Unit, the Laboratory Animal Center, and the Biomedicum Imaging Unit; and the Cell Imaging Core at the Turku Centre for Biotechnology.

\section{FUNDING STATEMENT:}

This study was supported by a Biomedicum Helsinki Foundation grant to IF, grants from the Sigrid Jusélius Foundation, Finska Läkaresällskapet and Paavo Nurmi Foundation to PPL, grants from Finnish Foundation for Cardiovascular Research, Academy of Finland (grant number 257545), Magnus Ehrnrooth Foundation and Jane and Aatos Erkko Foundation to MJ, grants from Academy of Finland, Sigrid Juselius Foundation, Novo Nordisk Foundation and Turku University Hospital to JT, Emil Aaltonen Fellowship to JAM, and grants from the Academy of Finland (grant numbers 25996, 263870 and 292789), Biocentrum Helsinki, and the Sigrid Jusélius Foundation to LK.

Biomedicum Helsinki-säätiö http://dx.doi.org/10.13039/501100003756, na, Imrul Faisal; Sigrid Juséliuksen Säätiö http://dx.doi.org/10.13039/501100006306, na, Pirkka-Pekka Laurila; Finska Läkaresällskapet http://dx.doi.org/10.13039/100010135, na, Pirkka-Pekka Laurila; Paavo Nurmen Säätiö http://dx.doi.org/10.13039/501100008484, na, Pirkka-Pekka Laurila; 
Sydäntutkimussäätiö http://dx.doi.org/10.13039/501100005633, na, Matti Jauhiainen; Academy of Finland, 257545, Matti Jauhiainen; Magnus Ehrnroothin Säätiö http://dx.doi.org/10.13039/501100004155, na, Matti Jauhiainen; Jane ja Aatos Erkon Säätiö http://dx.doi.org/10.13039/501100004012, na, Matti Jauhiainen; Academy of Finland, na, Jorma Toppari; Sigrid Juséliuksen Säätiö http://dx.doi.org/10.13039/501100006306, na, Jorma Toppari; Novo Nordisk Fonden http://dx.doi.org/10.13039/501100009708, na, Jorma Toppari; Turun Yliopistollinen Keskussairaala http://dx.doi.org/10.13039/501100011797, na, Jorma Toppari; Emil Aaltosen Säätiö http://dx.doi.org/10.13039/501100004756, na, Juho-Antti Mäkelä; Academy of Finland , 25996, 263870 and 292789, Liisa Kauppi; Biocentrum Helsinki, na, Liisa Kauppi; Sigrid Juséliuksen Säätiö http://dx.doi.org/10.13039/501100006306, na, Liisa Kauppi

AUTHOR CONTRIBUTIONS:

\begin{tabular}{|c|l|}
\hline Contributor Role & \\
\hline Conceptualization & IF, JAM, LK \\
\hline Data Curation & IF, SCM, GH, PPL, MJ, JAM, LK \\
\hline Formal Analysis & IF, JAM \\
\hline Funding Acquisition & IF, PPL, MJ, JT, JAM, LK \\
\hline Investigation & IF, SCM, GH, MIT, PPL, MAT, JAM \\
\hline Methodology & IF, SCM, GH, MIT, EA, PPL, MAT, JAM, LK \\
\hline Project Administration & IF, JAM, LK \\
\hline Resources & IF, GH, MJ, JT, JAM, LK \\
\hline Software & IF, GH, JAM \\
\hline Supervision & JAM, LK \\
\hline Validation & IF, SCM, JAM \\
\hline Visualization & IF, GH, SCM, JAM \\
\hline Writing - Review \& Editing & IF, JAM \\
\hline
\end{tabular}

* equal contribution

\# to whom correspondence should be addressed

\section{DISCLOSURE SUMMARY}

The Endocrine Society and its journals are committed to ensuring the integrity of all their activities. The Disclosure Policy for journal contributors requires that each author disclose all relevant financial and other interests that might be construed as resulting in an actual, potential, or apparent conflict in the author's role as a contributor to the journal, regardless of amount or value. Nothing in the disclosure statement shall be regarded as creating a presumption of impropriety in the existence of financial interests or other relationships. The purpose is to inform peer reviewers and readers of the existence of financial relationships pertinent to the article in the interest of the full transparency of the peer review and publication processes. If the paper is accepted for publication in the journal to which it is submitted, all disclosures will appear in all versions of the article. 
We certify that neither co-authors have a conflict of interest as described above that is relevant to the subject matter or materials included in this Work.

\section{REFERENCES}

1. de Rooij DG. The nature and dynamics of spermatogonial stem cells. Development 2017;144(17):3022-30 doi: 10.1242/dev.146571[published Online First: Epub Date]|. 2. Carrieri C, Comazzetto S, Grover A, et al. A transit-amplifying population underpins the efficient regenerative capacity of the testis. J Exp Med 2017;214(6):1631-41 doi: 10.1084/jem.20161371[published Online First: Epub Date]|.

3. Hara K, Nakagawa T, Enomoto H, et al. Mouse spermatogenic stem cells continually interconvert between equipotent singly isolated and syncytial states. Cell Stem Cell 2014;14(5):658-72 doi: 10.1016/j.stem.2014.01.019[published Online First: Epub Date]|. 4. Nakagawa T, Nabeshima Y, Yoshida S. Functional identification of the actual and potential stem cell compartments in mouse spermatogenesis. Dev Cell 2007;12(2):195-206 doi: 10.1016/j.devcel.2007.01.002[published Online First: Epub Date]|.

5. Nakagawa T, Sharma M, Nabeshima Y, Braun RE, Yoshida S. Functional hierarchy and reversibility within the murine spermatogenic stem cell compartment. Science 2010;328(5974):62-7 doi: 10.1126/science.1182868[published Online First: Epub Date]|. 6. La HM, Makela JA, Chan AL, et al. Identification of dynamic undifferentiated cell states within the male germline. Nat Commun 2018;9(1):2819 doi: 10.1038/s41467-018-04827z[published Online First: Epub Date]|.

7. de Rooij DG, Russell LD. All you wanted to know about spermatogonia but were afraid to ask. J Androl 2000;21(6):776-98

8. Tegelenbosch RA, de Rooij DG. A quantitative study of spermatogonial multiplication and stem cell renewal in the C3H/101 F1 hybrid mouse. Mutat Res 1993;290(2):193-200

9. de Rooij DG, Griswold MD. Questions about spermatogonia posed and answered since 2000. J Androl 2012;33(6):1085-95 doi: 10.2164/jandrol.112.016832[published Online First: Epub Date]|.

10. Franca LR, Hess RA, Dufour JM, Hofmann MC, Griswold MD. The Sertoli cell: one hundred fifty years of beauty and plasticity. Andrology 2016;4(2):189-212 doi:

10.1111/andr.12165[published Online First: Epub Date]|.

11. Meng X, Lindahl M, Hyvonen ME, et al. Regulation of cell fate decision of undifferentiated spermatogonia by GDNF. Science 2000;287(5457):1489-93

12. Sharma M, Braun RE. Cyclical expression of GDNF is required for spermatogonial stem cell homeostasis. Development 2018 doi: 10.1242/dev.151555[published Online First: Epub Date]|.

13. Chen LY, Brown PR, Willis WB, Eddy EM. Peritubular myoid cells participate in male mouse spermatogonial stem cell maintenance. Endocrinology 2014;155(12):4964-74 doi: 10.1210/en.2014-1406[published Online First: Epub Date]|.

14. Makela JA, Saario V, Bourguiba-Hachemi S, et al. Hedgehog signalling promotes germ cell survival in the rat testis. Reproduction 2011;142(5):711-21 doi: 10.1530/REP-11-

0110[published Online First: Epub Date]|.

15. Sato T, Aiyama Y, Ishii-Inagaki M, et al. Cyclical and patch-like GDNF distribution along the basal surface of Sertoli cells in mouse and hamster testes. PLoS One 2011;6(12):e28367 doi: 10.1371/journal.pone.0028367[published Online First: Epub Date]|. 16. Tadokoro Y, Yomogida K, Ohta H, Tohda A, Nishimune Y. Homeostatic regulation of germinal stem cell proliferation by the GDNF/FSH pathway. Mech Dev 2002;113(1):29-39 17. Ventela S, Makela JA, Kulmala J, Westermarck J, Toppari J. Identification and regulation of a stage-specific stem cell niche enriched by Nanog-positive spermatogonial stem cells in 
the mouse testis. Stem Cells 2012;30(5):1008-20 doi: 10.1002/stem.1077[published Online First: Epub Date]|.

18. Bhang DH, Kim BJ, Kim BG, et al. Testicular endothelial cells are a critical population in the germline stem cell niche. Nat Commun 2018;9(1):4379 doi: 10.1038/s41467-018-06881z[published Online First: Epub Date]|.

19. Kitadate Y, Jorg DJ, Tokue M, et al. Competition for Mitogens Regulates Spermatogenic Stem Cell Homeostasis in an Open Niche. Cell Stem Cell 2019;24(1):79-92 e6 doi: 10.1016/j.stem.2018.11.013[published Online First: Epub Date]|.

20. Buaas FW, Kirsh AL, Sharma M, et al. Plzf is required in adult male germ cells for stem cell self-renewal. Nat Genet 2004;36(6):647-52 doi: 10.1038/ng1366[published Online First: Epub Date]|.

21. Costoya JA, Hobbs RM, Barna M, et al. Essential role of Plzf in maintenance of spermatogonial stem cells. Nat Genet 2004;36(6):653-9 doi: 10.1038/ng1367[published Online First: Epub Date]|.

22. Falender AE, Freiman RN, Geles KG, et al. Maintenance of spermatogenesis requires TAF4b, a gonad-specific subunit of TFIID. Genes Dev 2005;19(7):794-803 doi: 10.1101/gad.1290105[published Online First: Epub Date]|.

23. Hobbs RM, Fagoonee S, Papa A, et al. Functional antagonism between Sall4 and Plzf defines germline progenitors. Cell Stem Cell 2012;10(3):284-98 doi:

10.1016/j.stem.2012.02.004[published Online First: Epub Date]|.

24. Chan AL, La HM, Legrand JMD, et al. Germline Stem Cell Activity Is Sustained by SALL4-Dependent Silencing of Distinct Tumor Suppressor Genes. Stem Cell Reports 2017;9(3):956-71 doi: 10.1016/j.stemcr.2017.08.001[published Online First: Epub Date]|. 25. Goertz MJ, Wu Z, Gallardo TD, Hamra FK, Castrillon DH. Foxo1 is required in mouse spermatogonial stem cells for their maintenance and the initiation of spermatogenesis. J Clin Invest 2011;121(9):3456-66 doi: 10.1172/JCI57984[published Online First: Epub Date]|. 26. Gregor PD, Sawadogo M, Roeder RG. The adenovirus major late transcription factor USF is a member of the helix-loop-helix group of regulatory proteins and binds to DNA as a dimer. Genes Dev 1990;4(10):1730-40

27. Sirito M, Lin Q, Maity T, Sawadogo M. Ubiquitous expression of the 43- and 44-kDa forms of transcription factor USF in mammalian cells. Nucleic acids research 1994;22(3):427-33

28. Bendall AJ, Molloy PL. Base preferences for DNA binding by the bHLH-Zip protein USF: effects of $\mathrm{MgCl} 2$ on specificity and comparison with binding of Myc family members. Nucleic acids research 1994;22(14):2801-10

29. Sirito M, Walker S, Lin Q, Kozlowski MT, Klein WH, Sawadogo M. Members of the USF family of helix-loop-helix proteins bind DNA as homo- as well as heterodimers. Gene expression 1992;2(3):231-40

30. Wood MA, Mukherjee P, Toocheck CA, Walker WH. Upstream stimulatory factor induces Nr5a1 and Shbg gene expression during the onset of rat Sertoli cell differentiation. Biology of reproduction 2011;85(5):965-76 doi: 10.1095/biolreprod.111.093013[published Online First: Epub Date]|.

31. Isotalo K, Kok EH, Luoto TM, et al. Upstream transcription factor 1 (USF1) polymorphisms associate with Alzheimer's disease-related neuropathological lesions: Tampere Autopsy Study. Brain Pathol 2012;22(6):765-75 doi: 10.1111/j.17503639.2012.00586.x[published Online First: Epub Date]|. 32. Pajukanta P, Lilja HE, Sinsheimer JS, et al. Familial combined hyperlipidemia is associated with upstream transcription factor 1 (USF1). Nat Genet 2004;36(4):371-6 doi: 10.1038/ng1320[published Online First: Epub Date]|. 
33. Park S, Liu X, Davis DR, Sigmund CD. Gene trapping uncovers sex-specific mechanisms for upstream stimulatory factors 1 and 2 in angiotensinogen expression. Hypertension 2012;59(6):1212-9 doi: 10.1161/HYPERTENSIONAHA.112.192971[published Online First: Epub Date]|.

34. Shibata N, Ohnuma T, Higashi S, et al. Genetic association between USF 1 and USF 2 gene polymorphisms and Japanese Alzheimer's disease. J Gerontol A Biol Sci Med Sci 2006;61(7):660-2

35. Laurila PP, Soronen J, Kooijman S, et al. USF1 deficiency activates brown adipose tissue and improves cardiometabolic health. Sci Transl Med 2016;8(323):323ra13 doi:

10.1126/scitranslmed.aad0015[published Online First: Epub Date]|.

36. Faisal I, Cisneros-Montalvo S, Hamer G, et al. Data from: Transcription factor USF1 is required for maintenance of germline stem cells in male mice.

https://dx.doi.org/10.6084/m9.figshare.7670807. Figshare 2019 doi:

10.6084/m9.figshare.7670807[published Online First: Epub Date]|.

37. RRID:AB_11156085.

38. RRID:AB_639330.

39. RRID:AB_627663.

40. RRID:AB_2108747.

41. RRID:AB_10854564.

42. RRID:AB_2239761.

43. RRID:AB_2574463.

44. RRID:AB_2216233.

45. RRID:AB_2304760.

46. RRID:AB_2213986.

47. RRID:AB_2110307.

48. RRID:AB_399174.

49. RRID:AB_1149786.

50. Kotaja N, Kimmins S, Brancorsini S, et al. Preparation, isolation and characterization of stage-specific spermatogenic cells for cellular and molecular analysis. Nat Methods 2004;1(3):249-54 doi: 10.1038/nmeth1204-249[published Online First: Epub Date]|. 51. Toppari J, Parvinen M. In vitro differentiation of rat seminiferous tubular segments from defined stages of the epithelial cycle morphologic and immunolocalization analysis. $\mathbf{J}$ Androl 1985;6(6):334-43

52. Faisal I, Kauppi L. Reduced MAD2 levels dampen the apoptotic response to nonexchange sex chromosomes and lead to sperm aneuploidy. Development 2017;144(11):198896 doi: 10.1242/dev.149492[published Online First: Epub Date]|.

53. Ketola I, Anttonen M, Vaskivuo T, Tapanainen JS, Toppari J, Heikinheimo M.

Developmental expression and spermatogenic stage specificity of transcription factors

GATA-1 and GATA-4 and their cofactors FOG-1 and FOG-2 in the mouse testis. Eur J Endocrinol 2002;147(3):397-406

54. Hobbs RM, La HM, Makela JA, Kobayashi T, Noda T, Pandolfi PP. Distinct germline progenitor subsets defined through Tsc2-mTORC1 signaling. EMBO Rep 2015;16(4):467-80 doi: 10.15252/embr.201439379[published Online First: Epub Date]|.

55. Hobbs RM, Seandel M, Falciatori I, Rafii S, Pandolfi PP. Plzf regulates germline progenitor self-renewal by opposing mTORC1. Cell 2010;142(3):468-79 doi:

10.1016/j.cell.2010.06.041[published Online First: Epub Date]|.

56. Shirakawa T, Yaman-Deveci R, Tomizawa S, et al. An epigenetic switch is crucial for spermatogonia to exit the undifferentiated state toward a Kit-positive identity. Development 2013;140(17):3565-76 doi: 10.1242/dev.094045[published Online First: Epub Date]|. 
57. Raverot G, Weiss J, Park SY, Hurley L, Jameson JL. Sox3 expression in undifferentiated spermatogonia is required for the progression of spermatogenesis. Dev Biol 2005;283(1):21525 doi: 10.1016/j.ydbio.2005.04.013[published Online First: Epub Date]|.

58. Makela JA, Toppari J. Spermatogenesis. In: Simoni M, Huhtaniemi I, eds. Endocrinology of the Testis and Male Reproduction: Springer, 2017:417-55.

59. Chang C, Chen YT, Yeh SD, et al. Infertility with defective spermatogenesis and hypotestosteronemia in male mice lacking the androgen receptor in Sertoli cells. Proceedings of the National Academy of Sciences of the United States of America 2004;101(18):6876-81 doi: 10.1073/pnas.0307306101[published Online First: Epub Date]|.

60. De Gendt K, Swinnen JV, Saunders PT, et al. A Sertoli cell-selective knockout of the androgen receptor causes spermatogenic arrest in meiosis. Proceedings of the National Academy of Sciences of the United States of America 2004;101(5):1327-32 doi: 10.1073/pnas.0308114100[published Online First: Epub Date]|. 61. Lyon MF, Hawkes SG. X-linked gene for testicular feminization in the mouse. Nature 1970;227(5264):1217-9

62. O'Hara L, McInnes K, Simitsidellis I, et al. Autocrine androgen action is essential for Leydig cell maturation and function, and protects against late-onset Leydig cell apoptosis in both mice and men. FASEB J 2015;29(3):894-910 doi: 10.1096/fj.14-255729[published Online First: Epub Date]|.

63. Welsh M, Saunders PT, Atanassova N, Sharpe RM, Smith LB. Androgen action via testicular peritubular myoid cells is essential for male fertility. FASEB J 2009;23(12):421830 doi: 10.1096/fj.09-138347[published Online First: Epub Date]|. 64. Orth JM, Gunsalus GL, Lamperti AA. Evidence from Sertoli cell-depleted rats indicates that spermatid number in adults depends on numbers of Sertoli cells produced during perinatal development. Endocrinology 1988;122(3):787-94 doi: 10.1210/endo-122-3787[published Online First: Epub Date]|.

65. Sharpe RM, Kerr JB, McKinnell C, Millar M. Temporal relationship between androgendependent changes in the volume of seminiferous tubule fluid, lumen size and seminiferous tubule protein secretion in rats. J Reprod Fertil 1994;101(1):193-8

66. Sharpe RM, McKinnell C, Kivlin C, Fisher JS. Proliferation and functional maturation of Sertoli cells, and their relevance to disorders of testis function in adulthood. Reproduction 2003;125(6):769-84

67. Sonne SB, Herlihy AS, Hoei-Hansen CE, et al. Identity of M2A (D2-40) antigen and gp36 (Aggrus, T1A-2, podoplanin) in human developing testis, testicular carcinoma in situ and germ-cell tumours. Virchows Arch 2006;449(2):200-6 doi: 10.1007/s00428-006-02234[published Online First: Epub Date]|.

68. Steger K, Rey R, Kliesch S, Louis F, Schleicher G, Bergmann M. Immunohistochemical detection of immature Sertoli cell markers in testicular tissue of infertile adult men: a preliminary study. Int J Androl 1996;19(2):122-8

69. Kumar TR, Wang Y, Lu N, Matzuk MM. Follicle stimulating hormone is required for ovarian follicle maturation but not male fertility. Nat Genet 1997;15(2):201-4 doi: 10.1038/ng0297-201[published Online First: Epub Date]|.

70. Tapanainen JS, Aittomaki K, Min J, Vaskivuo T, Huhtaniemi IT. Men homozygous for an inactivating mutation of the follicle-stimulating hormone (FSH) receptor gene present variable suppression of spermatogenesis and fertility. Nat Genet 1997;15(2):205-6 doi: 10.1038/ng0297-205[published Online First: Epub Date]|.

71. Hermann BP, Hornbaker K, Rice DA, Sawadogo M, Heckert LL. In vivo regulation of follicle-stimulating hormone receptor by the transcription factors upstream stimulatory factor 1 and upstream stimulatory factor 2 is cell specific. Endocrinology 2008;149(10):5297-306 doi: 10.1210/en.2007-1199[published Online First: Epub Date]|. 
72. Luo X, Ikeda Y, Parker KL. A cell-specific nuclear receptor is essential for adrenal and gonadal development and sexual differentiation. Cell 1994;77(4):481-90

73. Chen SR, Tang JX, Cheng JM, et al. Loss of Gata4 in Sertoli cells impairs the spermatogonial stem cell niche and causes germ cell exhaustion by attenuating chemokine signaling. Oncotarget 2015;6(35):37012-27 doi: 10.18632/oncotarget.6115[published Online First: Epub Date]|.

74. Kyronlahti A, Euler R, Bielinska M, et al. GATA4 regulates Sertoli cell function and fertility in adult male mice. Mol Cell Endocrinol 2011;333(1):85-95 doi:

10.1016/j.mce.2010.12.019[published Online First: Epub Date]|.

75. Minkina A, Matson CK, Lindeman RE, Ghyselinck NB, Bardwell VJ, Zarkower D. DMRT1 protects male gonadal cells from retinoid-dependent sexual transdifferentiation. Dev Cell 2014;29(5):511-20 doi: 10.1016/j.devcel.2014.04.017[published Online First: Epub Date]|.

76. Gao F, Maiti S, Alam N, et al. The Wilms tumor gene, Wt1, is required for Sox 9 expression and maintenance of tubular architecture in the developing testis. Proceedings of the National Academy of Sciences of the United States of America 2006;103(32):11987-92 doi: 10.1073/pnas.0600994103[published Online First: Epub Date]|.

77. Zhang L, Chen M, Wen Q, et al. Reprogramming of Sertoli cells to fetal-like Leydig cells by Wt1 ablation. Proceedings of the National Academy of Sciences of the United States of America 2015;112(13):4003-8 doi: 10.1073/pnas.1422371112[published Online First: Epub Date]|.

78. Makela JA, Toppari J. Seminiferous Cycle. In: Skinner M, Jegou B, eds. Encyclopedia of Reproduction: In press, 2018.

79. Yang QE, Kim D, Kaucher A, Oatley MJ, Oatley JM. CXCL12-CXCR4 signaling is required for the maintenance of mouse spermatogonial stem cells. J Cell Sci 2013;126(Pt 4):1009-20 doi: 10.1242/jcs.119826[published Online First: Epub Date]|.

80. Oatley JM, Oatley MJ, Avarbock MR, Tobias JW, Brinster RL. Colony stimulating factor 1 is an extrinsic stimulator of mouse spermatogonial stem cell self-renewal. Development 2009;136(7):1191-9 doi: 10.1242/dev.032243[published Online First: Epub Date]|. 81. Ishii K, Kanatsu-Shinohara M, Toyokuni S, Shinohara T. FGF2 mediates mouse spermatogonial stem cell self-renewal via upregulation of Etv5 and Bc16b through MAP2K1 activation. Development 2012;139(10):1734-43 doi: 10.1242/dev.076539[published Online First: Epub Date]|.

82. Hamra FK, Chapman KM, Nguyen D, Garbers DL. Identification of neuregulin as a factor required for formation of aligned spermatogonia. J Biol Chem 2007;282(1):721-30 doi: 10.1074/jbc.M608398200[published Online First: Epub Date]|.

83. Boyer A, Yeh JR, Zhang X, et al. CTNNB1 signaling in sertoli cells downregulates spermatogonial stem cell activity via WNT4. PLoS One 2012;7(1):e29764 doi:

10.1371/journal.pone.0029764[published Online First: Epub Date]|.

84. Tanaka T, Kanatsu-Shinohara M, Lei Z, Rao CV, Shinohara T. The Luteinizing Hormone-Testosterone Pathway Regulates Mouse Spermatogonial Stem Cell Self-Renewal by Suppressing WNT5A Expression in Sertoli Cells. Stem Cell Reports 2016;7(2):279-91 doi: 10.1016/j.stemcr.2016.07.005[published Online First: Epub Date]|.

85. Yeh JR, Zhang X, Nagano MC. Wnt5a is a cell-extrinsic factor that supports self-renewal of mouse spermatogonial stem cells. J Cell Sci 2011;124(Pt 14):2357-66 doi:

10.1242/jcs.080903[published Online First: Epub Date]|.

86. Takase HM, Nusse R. Paracrine Wnt/beta-catenin signaling mediates proliferation of undifferentiated spermatogonia in the adult mouse testis. Proceedings of the National Academy of Sciences of the United States of America 2016;113(11):E1489-97 doi: 10.1073/pnas.1601461113[published Online First: Epub Date]|. 
87. Carlomagno G, van Bragt MP, Korver CM, Repping S, de Rooij DG, van Pelt AM. BMP4-induced differentiation of a rat spermatogonial stem cell line causes changes in its cell adhesion properties. Biology of reproduction 2010;83(5):742-9 doi:

10.1095/biolreprod.110.085456[published Online First: Epub Date]|.

88. Yan W, Linderborg J, Suominen J, Toppari J. Stage-specific regulation of stem cell factor gene expression in the rat seminiferous epithelium. Endocrinology 1999;140(3):1499-504 doi: 10.1210/endo.140.3.6590[published Online First: Epub Date]|.

89. Chen C, Ouyang W, Grigura V, et al. ERM is required for transcriptional control of the spermatogonial stem cell niche. Nature 2005;436(7053):1030-4 doi:

10.1038/nature03894[published Online First: Epub Date]|.

90. Ikami K, Tokue M, Sugimoto R, et al. Hierarchical differentiation competence in response to retinoic acid ensures stem cell maintenance during mouse spermatogenesis. Development 2015;142(9):1582-92 doi: 10.1242/dev.118695[published Online First: Epub Date]|.

91. Tokue M, Ikami K, Mizuno S, et al. SHISA6 Confers Resistance to DifferentiationPromoting Wnt/beta-Catenin Signaling in Mouse Spermatogenic Stem Cells. Stem Cell Reports 2017;8(3):561-75 doi: 10.1016/j.stemcr.2017.01.006[published Online First: Epub Date]|.

92. Caires KC, de Avila J, McLean DJ. Endocrine regulation of spermatogonial stem cells in the seminiferous epithelium of adult mice. Biores Open Access 2012;1(5):222-30 doi:

10.1089/biores.2012.0259[published Online First: Epub Date]|.

93. Endo T, Freinkman E, de Rooij DG, Page DC. Periodic production of retinoic acid by meiotic and somatic cells coordinates four transitions in mouse spermatogenesis. Proceedings of the National Academy of Sciences of the United States of America 2017;114(47):E10132E41 doi: 10.1073/pnas.1710837114[published Online First: Epub Date]|.

94. Hogarth CA, Arnold S, Kent T, Mitchell D, Isoherranen N, Griswold MD. Processive pulses of retinoic acid propel asynchronous and continuous murine sperm production.

Biology of reproduction 2015;92(2):37 doi: 10.1095/biolreprod.114.126326[published Online First: Epub Date]|.

95. Hogarth CA, Griswold MD. Retinoic acid regulation of male meiosis. Curr Opin Endocrinol Diabetes Obes 2013;20(3):217-23 doi: 10.1097/MED.0b013e32836067cf[published Online First: Epub Date]|.

96. Hasegawa K, Namekawa SH, Saga Y. MEK/ERK signaling directly and indirectly contributes to the cyclical self-renewal of spermatogonial stem cells. Stem Cells 2013;31(11):2517-27 doi: 10.1002/stem.1486[published Online First: Epub Date]|. 97. Ding LJ, Yan GJ, Ge QY, et al. FSH acts on the proliferation of type A spermatogonia via Nur77 that increases GDNF expression in the Sertoli cells. FEBS Lett 2011;585(15):2437-44 doi: 10.1016/j.febslet.2011.06.013[published Online First: Epub Date]|.

98. Oduwole OO, Vydra N, Wood NE, et al. Overlapping dose responses of spermatogenic and extragonadal testosterone actions jeopardize the principle of hormonal male contraception. FASEB J 2014;28(6):2566-76 doi: 10.1096/fj.13-249219[published Online First: Epub Date]|.

99. Bremner WJ, Millar MR, Sharpe RM, Saunders PT. Immunohistochemical localization of androgen receptors in the rat testis: evidence for stage-dependent expression and regulation by androgens. Endocrinology 1994;135(3):1227-34 doi:

10.1210/endo.135.3.8070367[published Online First: Epub Date]|. 100. Hale TK, Braithwaite AW. Identification of an upstream region of the mouse p53 promoter critical for transcriptional expression. Nucleic acids research 1995;23(4):663-9 
101. Jaiswal AS, Narayan S. Upstream stimulating factor-1 (USF1) and USF2 bind to and activate the promoter of the adenomatous polyposis coli (APC) tumor suppressor gene. J Cell Biochem 2001;81(2):262-77

102. Pezzolesi MG, Zbuk KM, Waite KA, Eng C. Comparative genomic and functional analyses reveal a novel cis-acting PTEN regulatory element as a highly conserved functional E-box motif deleted in Cowden syndrome. Hum Mol Genet 2007;16(9):1058-71 doi: 10.1093/hmg/ddm053[published Online First: Epub Date]|. 103. Reisman D, Rotter V. The helix-loop-helix containing transcription factor USF binds to and transactivates the promoter of the p53 tumor suppressor gene. Nucleic acids research 1993;21(2):345-50

104. Bouafia A, Corre S, Gilot D, Mouchet N, Prince S, Galibert MD. p53 requires the stress sensor USF1 to direct appropriate cell fate decision. PLoS Genet 2014;10(5):e1004309 doi: 10.1371/journal.pgen.1004309[published Online First: Epub Date]|.

105. Luo X, Sawadogo M. Antiproliferative properties of the USF family of helix-loop-helix transcription factors. Proceedings of the National Academy of Sciences of the United States of America 1996;93(3):1308-13

106. Corre S, Galibert MD. Upstream stimulating factors: highly versatile stress-responsive transcription factors. Pigment Cell Res 2005;18(5):337-48 doi: 10.1111/j.16000749.2005.00262.x[published Online First: Epub Date]|.

107. Sirito M, Lin Q, Deng JM, Behringer RR, Sawadogo M. Overlapping roles and asymmetrical cross-regulation of the USF proteins in mice. Proceedings of the National Academy of Sciences of the United States of America 1998;95(7):3758-63

108. Koubova J, Menke DB, Zhou Q, Capel B, Griswold MD, Page DC. Retinoic acid regulates sex-specific timing of meiotic initiation in mice. Proceedings of the National Academy of Sciences of the United States of America 2006;103(8):2474-9 doi: 10.1073/pnas.0510813103[published Online First: Epub Date]|.

Figure 1: USF1 expression is limited to testicular somatic cells and a subset of spermatogonia. A-B) RT-qPCR analysis of Usfl expression from whole testis RNA of wildtype control mice at the indicated timepoints (A) and from total RNA of indicated pooled seminiferous tubule epithelial stages (B). Usf1 expression levels were normalized to respective $\alpha$-tubulin levels in A. Data in B were normalized against Wt1, which is uniformly expressed by Sertoli cells independent of epithelial stage. Bars represent mean \pm s.d. and $p$ values are from unpaired $t$-tests. Asterisks: $*=p<0.05$, $* *=p<0.01$ and $* * *=p<0.001$. C) Testis cross-sections of the indicated genotypes were stained with DAPI and antibodies against USF1, GATA1 and WT1. GATA1 displayed a stage-dependent pattern of expression in Sertoli cells, and therefore GATA1 expression, unlike WT1, was limited to Sertoli cells of certain seminiferous tubules. Immunofluorescent triple-staining confirmed abundant expression of USF1 in Sertoli cells. A low level of USF1 was also detected in the testicular interstitium. USF1 expression was undetectable in the knockout testes. D-E) Representative whole-mount immunofluorescence stainings of WT adult seminiferous tubules by antibodies against PLZF and USF1. USF1 was detected in PLZF-negative Sertoli cells plus in PLZFpositive undifferentiated $\mathrm{A}_{s}, \mathrm{~A}_{\mathrm{pr}}$ and $\mathrm{A}_{\mathrm{al}}$ (cysts of 4,8 and 16 cells) spermatogonia. See Supplementary Figure 1 for more detailed characterization of the USF1-positive spermatogonial subpopulation. Scale bars $100 \mu \mathrm{m}$ in C and $50 \mu \mathrm{m}$ in D-E. F) Summary of the whole-mount IF staining included in this study. USF1 is ubiquitously expressed by Sertoli cells. USF1 expression in spermatogonia is restricted to $A_{\text {undiff }}$ spermatogonia and to early (up to A4) differentiating spermatogonia. Spermatogonial expression of USF1 closely follows that of PLZF. Solid line indicates ubiquitous readily detectable expression, whereas downregulation of protein expression is marked with dotted line. For GFR $\alpha 1$, the dotted line 
is used throughout to illustrate that GFR $\alpha 1$ is limited to the SSC subset of $A_{\text {undiff. As }}$ suggested by IF data, Usfl does not display a seminiferous epithelial stage-regulated pattern of expression (B).

Figure 2: USF1 is required for normal testis growth. A) One-week old male pups of the indicated genotypes. These three males were from the same litter. B) Representative testes of indicated genotypes from eight-week old males. C) Testis weight of control and $U s f 1^{-/}$mice at indicated ages. D) Relative testis weight of same mice represented in C. In both C and D, a minimum of three animals per group were included per timepoint, bars represent mean \pm s.d. and $p$ values are from unpaired $t$-tests. E-N) Progressive degeneration of the seminiferous epithelium in the absence of Usf1. E-J) Representative testis cross-sections of the indicated genotypes. E-G) Testis sections from 12-week adult controls (E) and from $U s f^{-1-}$ mice at 12 (F) and 30 weeks of age $(\mathrm{G})$ stained with hematoxylin and eosin to show morphology of seminiferous tubules. Already at 12 weeks a substantial proportion of seminiferous tubules of $U s f 1^{-/-}$mice had degenerated and hosted only the basal layer, or lacked one or more of the hierarchical layers of differentiating germ cells $(F)$. Tubule degeneration became more prevalent with age $(\mathrm{G})$. H-J) Cross-sections of individual seminiferous tubules representing normal spermatogenesis at stage VII-VIII of the seminiferous epithelial cycle. Compared to seminiferous tubules in controls $(\mathrm{H})$, reduced cellularity is observed in otherwise normallooking seminiferous tubules of $U s f 1^{-/}$mice (I-J). Scale bars: $500 \mu \mathrm{m}(\mathrm{E}-\mathrm{G}), 50 \mu \mathrm{m}(\mathrm{H}-\mathrm{J})$. K$\mathrm{N})$ Evaluation of spermatogenic defect from testis cross-sections. Error bars represent mean \pm s.d. and $p$ values are from unpaired $t$ tests. Asterisks: $*=p<0.05, * *=p<0.01$ and $* * *$ $=p<0.001$. See also Supplementary Figure 3 for scoring criteria.

Figure 3: Endocrine regulation of the $U \boldsymbol{s} \boldsymbol{f} \boldsymbol{I}^{-/-}$testis. A-C) Serum hormonal levels in mice of the indicated genotypes. Although serum levels of LH (A) and FSH (B) were higher in $U s f 1^{-1-}$ mice, there was no difference in serum testosterone (C) levels. D) Intratesticular levels of testosterone were significantly elevated in the $U s f 1^{-/-}$testes when compared to wildtype control mice. All the hormonal levels in A-D are measured from minimum 4 animals per genotype and at 12 weeks age. E) Quantitation of Leydig cells at different timepoints. F) Quantitation of proliferative Leydig cells at the indicated timepoints by an antibody against Ki67. G) LH receptor ( $\mathrm{Lhcgr}$ ) expression by RT-qPCR analysis, $\alpha$-tubulin was used as a normalization control. H-I) Assessment of androgen receptor (AR) expression by immunohistochemistry (H) and RT-qPCR (I). AR was found normally expressed within the different testicular somatic cell types. Insets 1-4 in (H) show comparable AR expression in Sertoli/myoid cells (insets 1 and 3) and Leydig/myoid cells (insets 2 and 4) between WT control and $U s f 1^{-/}$mice. J) $A R$ expression at the indicated seminiferous tubule epithelial stages as normalized to $W t 1$, which is uniformly expressed by Sertoli cells independent of the epithelial stage. Error bars represent mean \pm s.d. and $p$ values are from unpaired $t$-tests. Asterisks: $*=p<0.05, * *=p<0.01$ and $* * *=p<0.001$. Scale bars: $100 \mu \mathrm{m}(\mathrm{H})$ and $50 \mu \mathrm{m}$ [insets in $(\mathrm{H})]$.

Figure 4: Seminiferous epithelial stage-specific gene expression patterns are maintained in the absence of $\boldsymbol{U} \boldsymbol{s} \boldsymbol{f} 1$. A-D) Expression of select mRNAs: A) Fshr, B) Gatal, C) Sox9, and D) Stra 8 was assessed by RT-qPCR. To control for the observed differences in cellularity between $U s f 1^{-/}$and WT mice, data were normalized against Wt1 that is uniformly expressed by Sertoli cells independent of the epithelial stage. Seminiferous tubule segments representing stages II-V, VII-VIII and IX-XI were isolated by transillumination-assisted microdissection from 8-week old mice. Generally, expression of studied genes were maintained in a stage-wise manner between $U s f 1^{-/-}$and WT mice. However, for individual 
genes enhanced expression was observed at specific stages in the knockout tubules. Three animals per group were used in all experiments. Stra 8 was included in the experiment as an internal control since it is known to display a highly stage-dependent pattern of expression at stages VII-VIII of the seminiferous epithelial cycle [17 108]. Error bars represent mean \pm s.d and $p$ values are from unpaired $t$-tests. Asterisks: $*=p<0.05, * *=p<0.01$ and $* * *=$ $p<0.001$.

Figure 5: PLZF-positive cells are depleted with age in the $\boldsymbol{U} \boldsymbol{s} \boldsymbol{I}^{-/-}$testes. A) Testis crosssections, shown here from 12- and 25-week old mice, were stained with an antibody against PLZF at different timepoints. B) Quantitation of tubules hosting PLZF-positive cells in control and $U s f 1^{-/}$testes at the indicated ages. A minimum of two animals per timepoint were analyzed. Scale bars: $50 \mu \mathrm{m}$. C-D) Gdnf and $S c f$ expression levels at the indicated stages of the seminiferous epithelial cycle. Transcript levels were normalized to Wtl, which is uniformly expressed by Sertoli cells independent of the epithelial stage. A minimum of three animals per group was used in all experiments. Error bars present mean \pm s.d. and $p$ values are from unpaired $t$-tests. Asterisks: $*=p<0.05, * *=p<0.01$ and $* * *=p<0.001$.

Figure 6: Spermatogonial stem cells are hyperproliferative in the absence of $U s f 1$. A-B) Representative whole-mount IF staining of 8-week control (A) and $U s 1^{-/-}$(B) seminiferous tubules showing areas where GFR 1 1-positive cells were found accumulated. Only a subset of GFR $\alpha 1$-positive also stain for Ki67. GFR $\alpha 1$-negative cells are differentiating spermatogonia that are continuously engaged in the cell cycle and thus positive for Ki67. C) Assessment of proliferation within the GFR $\alpha 1$-positive undifferentiated spermatogonia. Blue arrow points at a Ki67-positive (proliferatively active) GFR $\alpha 1$-positive $A_{s}$ spermatogonium and yellow arrows indicate Ki67-negative (non-proliferative) GFR $\alpha 1$-positive $A_{\mathrm{s}}$ spermatogonia. GFR $\alpha 1$-positive/Ki67-positive $A_{\text {pr }}$ spermatogonia are indicated by the white arrow. D) Quantitation of Ki67-GFR $\alpha 1$ double-positive $A_{s}$ and $A_{\text {pr }}$ spermatogonia in mice of the indicated genotypes. Error bars represent mean \pm s.d. and $p$ values are from unpaired $t$-tests. ** $=p<0.01$. Scale bars $50 \mu \mathrm{m}$.

Figure 7: Proposed model for USF1-dependent, proliferation-coupled stem cell exhaustion. In the WT testis, stem cells continually exit (at stage II) and re-enter (at stage X) cell cycle as a result of the progress of the seminiferous epithelial cycle. Spermatogenesis is initiated (i.e. transition from $\mathrm{A}_{\text {undiff }}$ to type $\mathrm{A} 1$ differentiating spermatogonia) once every epithelial cycle at stages VII-VIII. A delicate balance between self-renewal vs. differentiation prevails and the stem cell population is maintained while a sufficient but not excessive number of differentiating progeny is simultaneously produced during every epithelial cycle, enabling lifelong sperm production from the SSC niche. In the $U s f 1^{-/}$testis stem cells become continually engaged in the cell cycle, resulting in their proliferation-coupled exhaustion and inability to maintain the stem cell pool. Once the niche is depleted of stem cells, germ cells are lost from the locale layer by layer as a result of seminiferous epithelial cycle progression and the spermatogenic program. Symbols used to indicate different germ cell types are described in Figure 1F. 

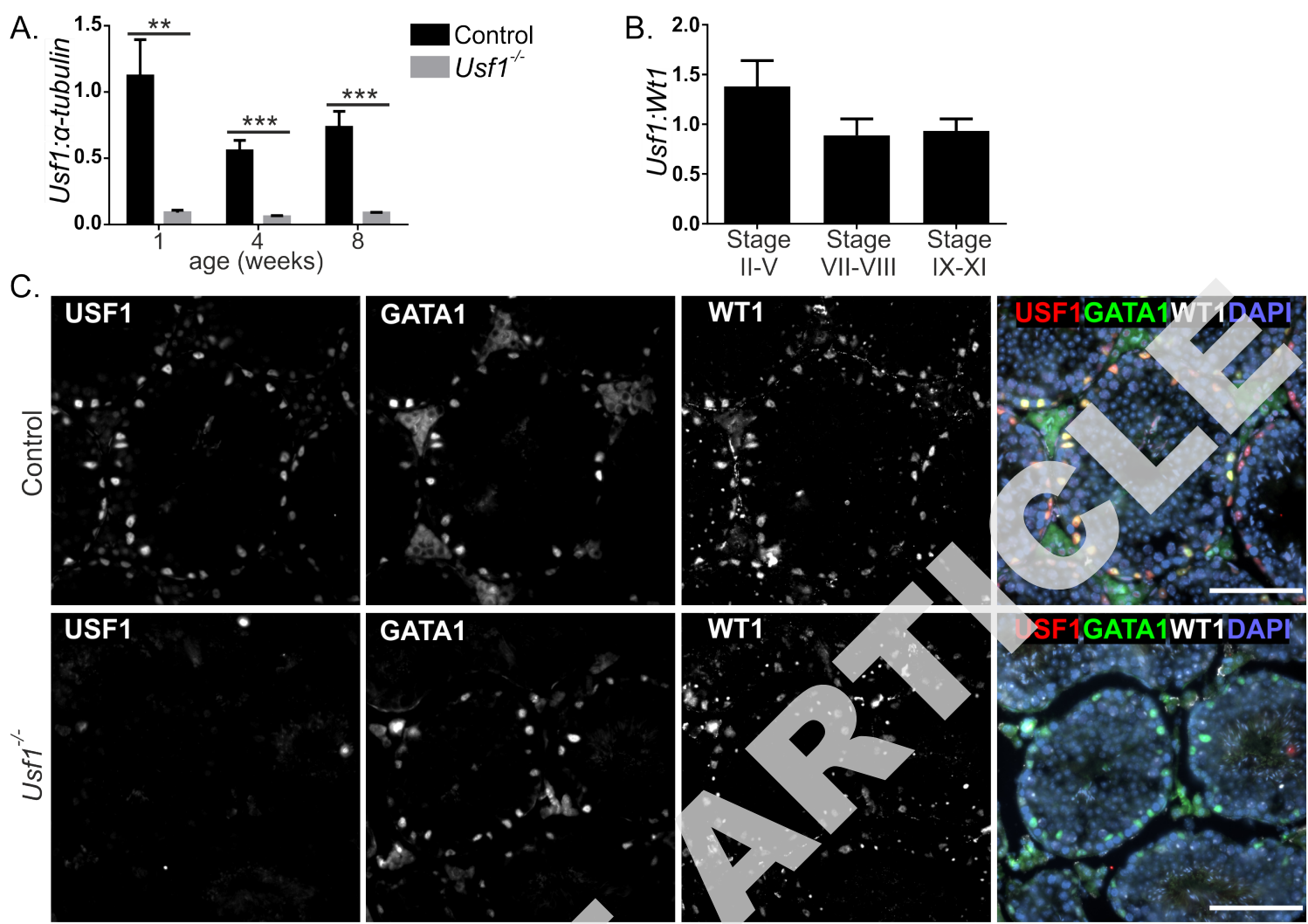

D. PLZFUSF1
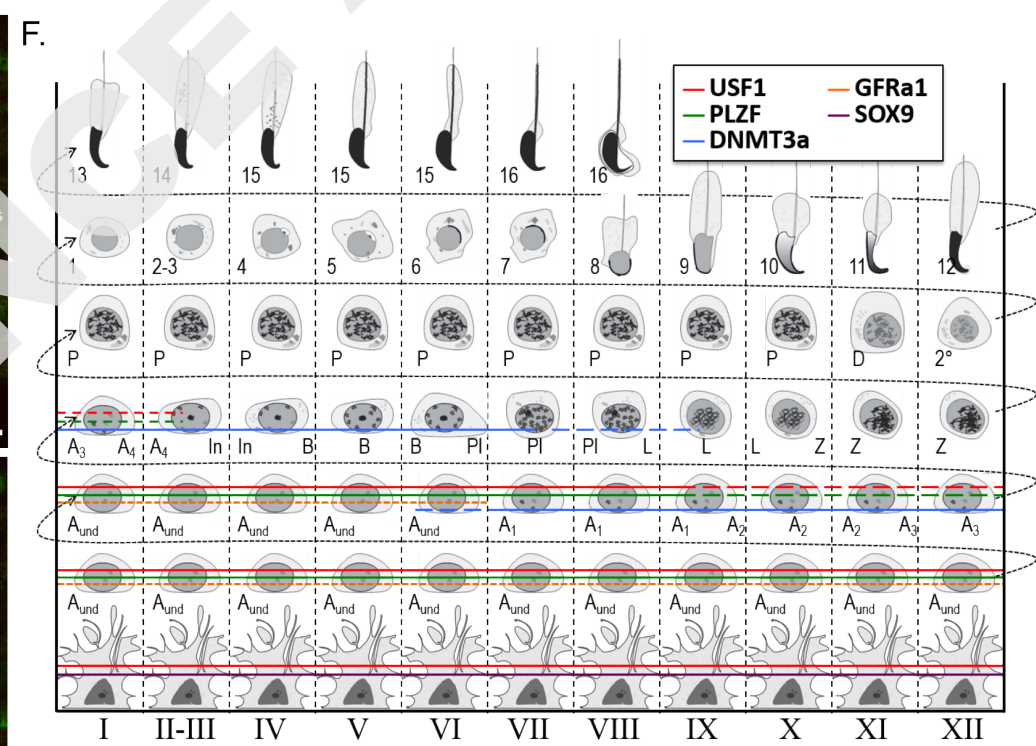

E.

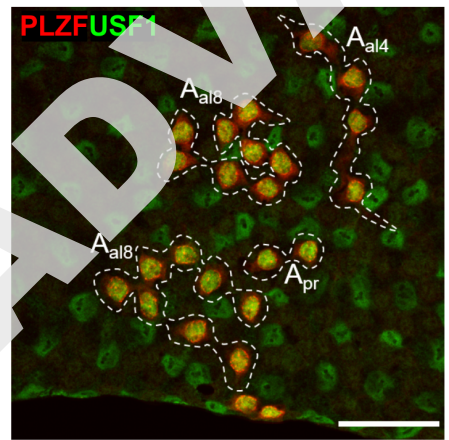


A.

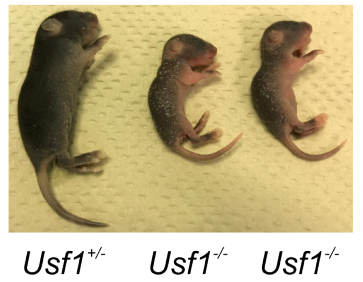

C.

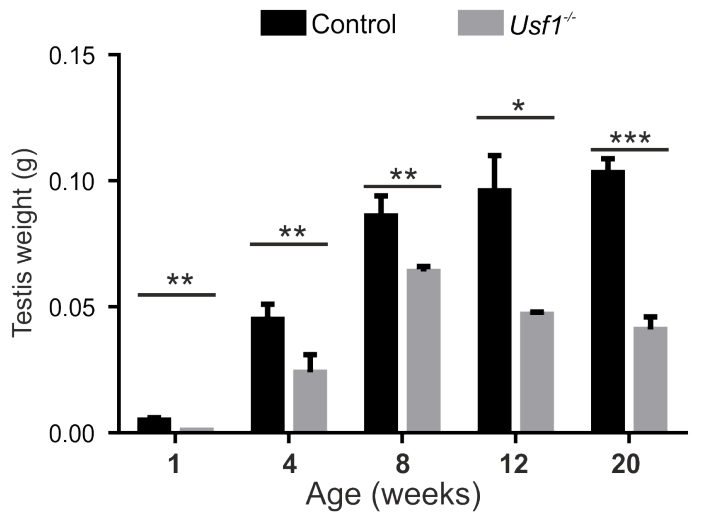

B.

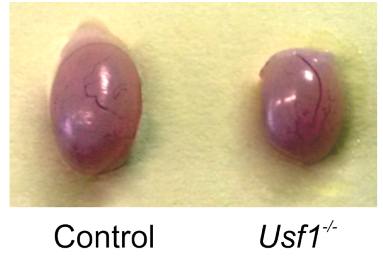

D.

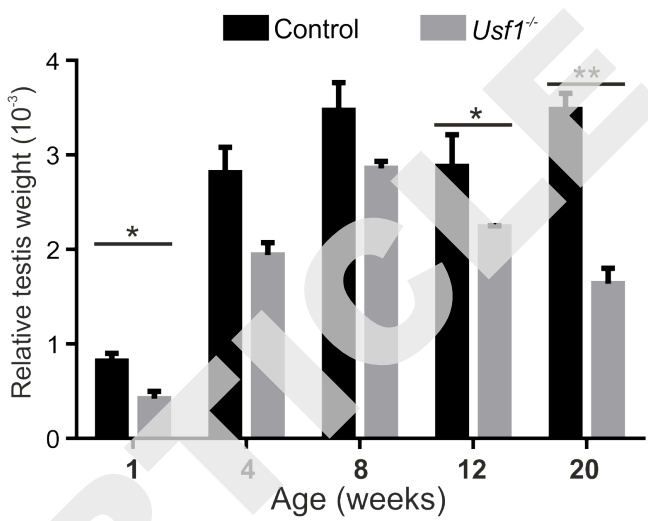

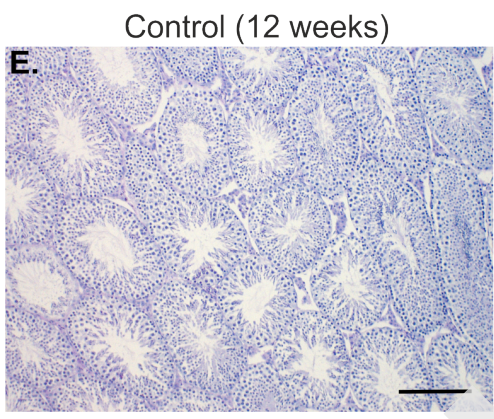

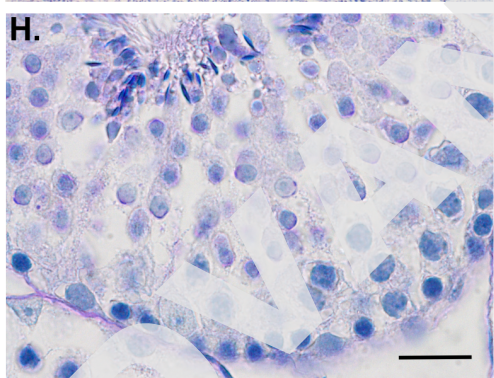

K.

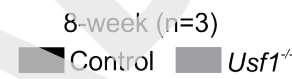

L.
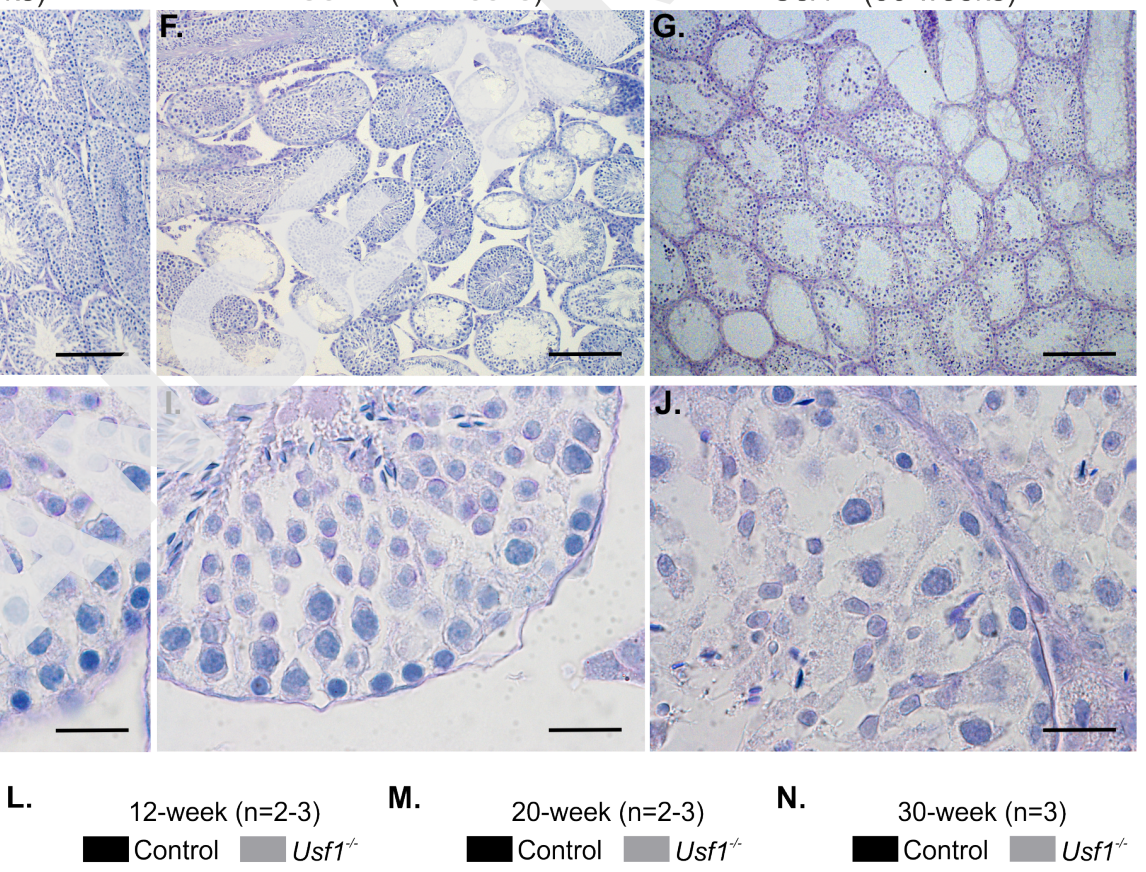

$\frac{U}{Z}$

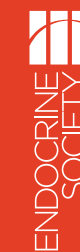


A.

B.

C. Testosterone (serum) D.

D. Testosterone (testis)
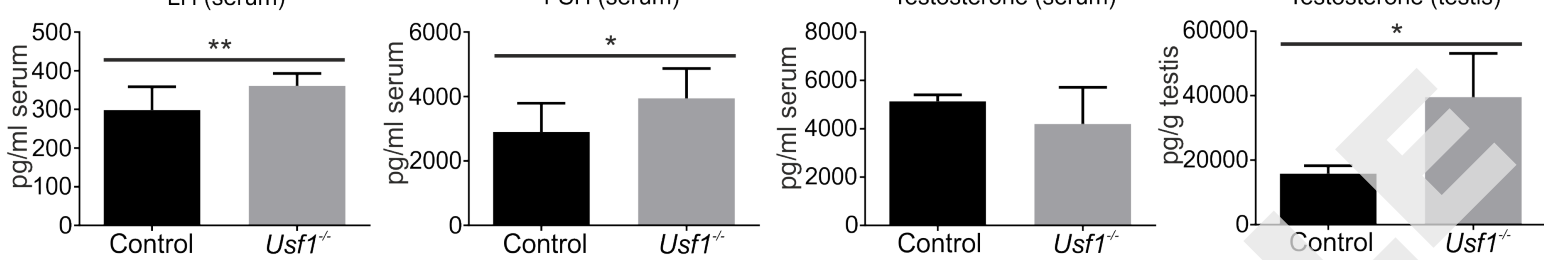

E

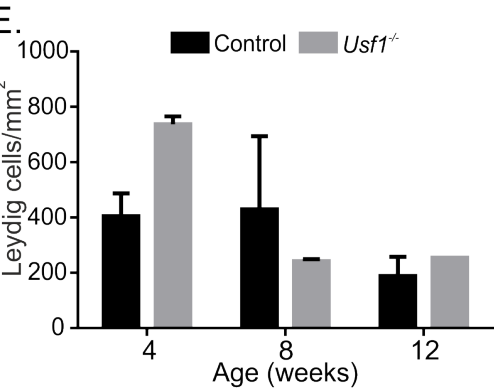

$\mathrm{H}$.
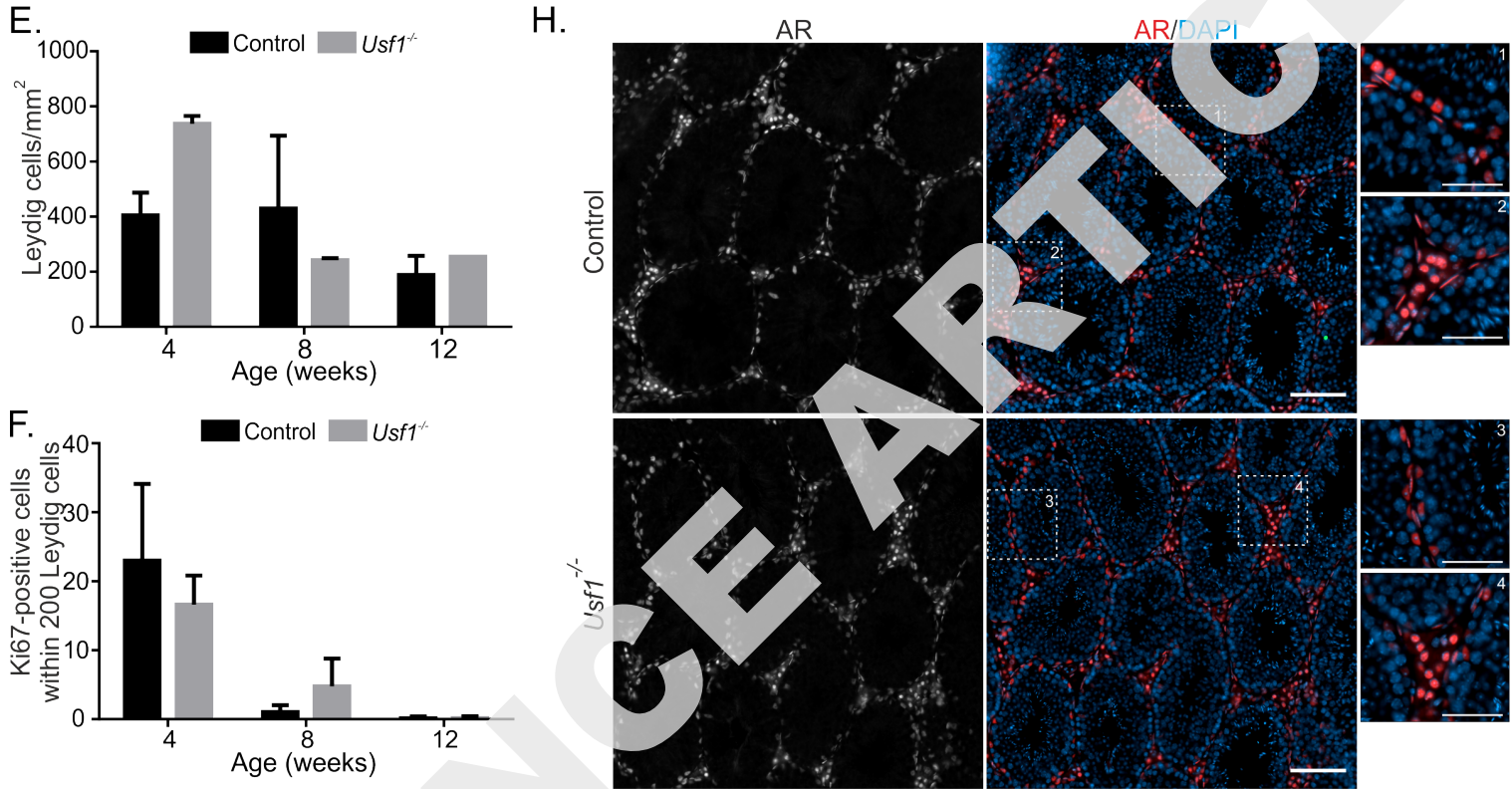

G.

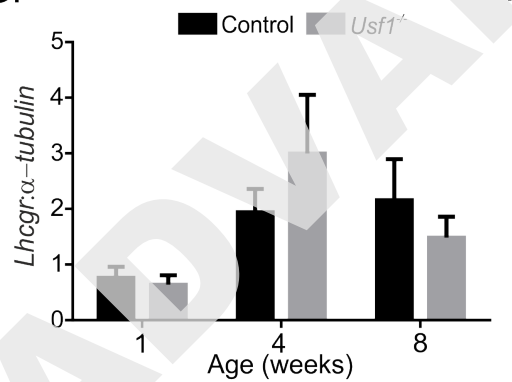

I.

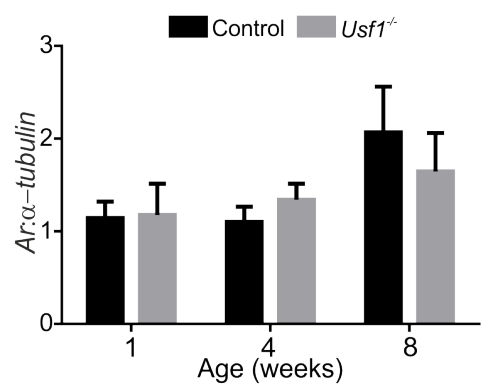

J.

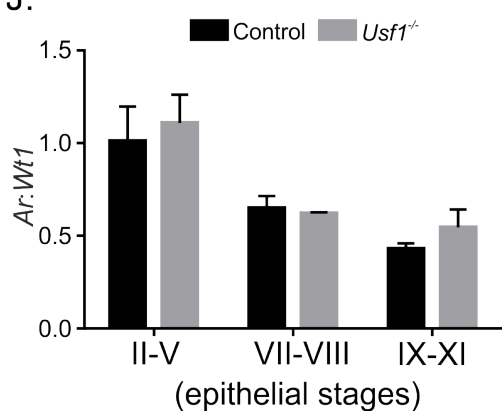

(epithelial stages) 

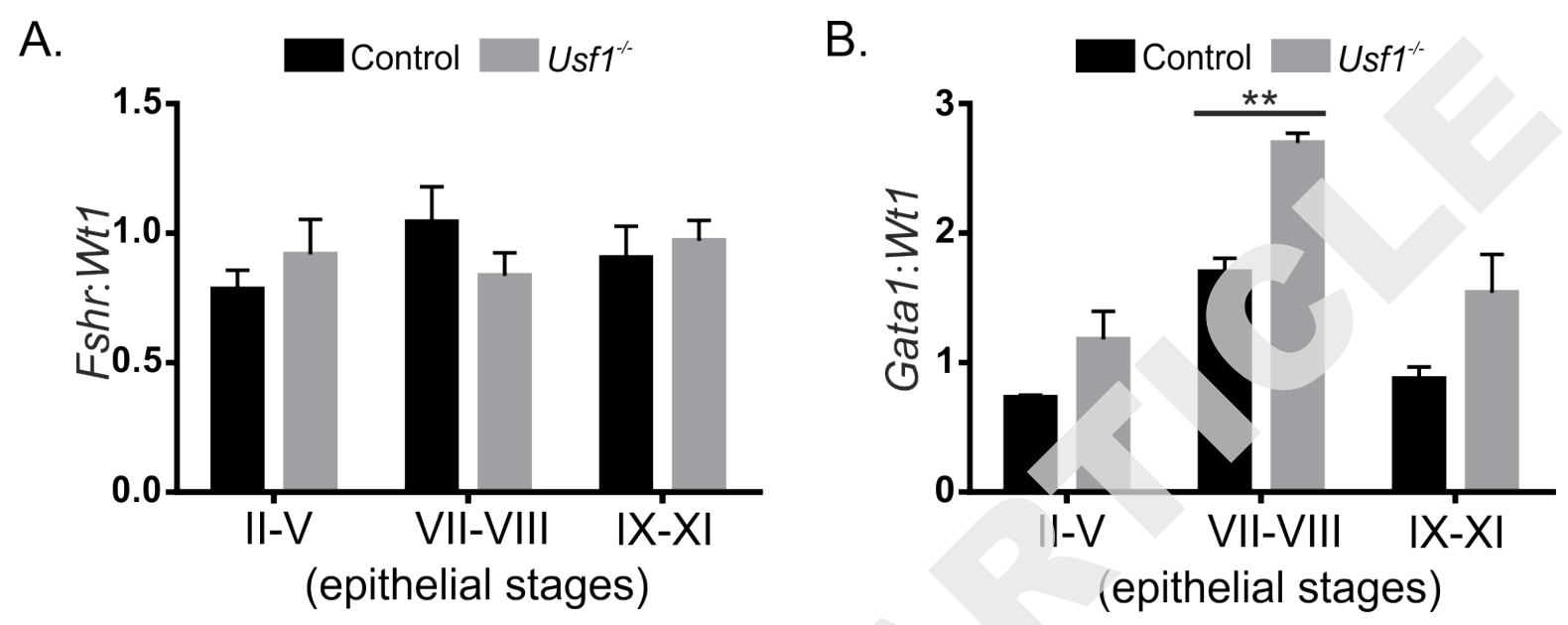

C.



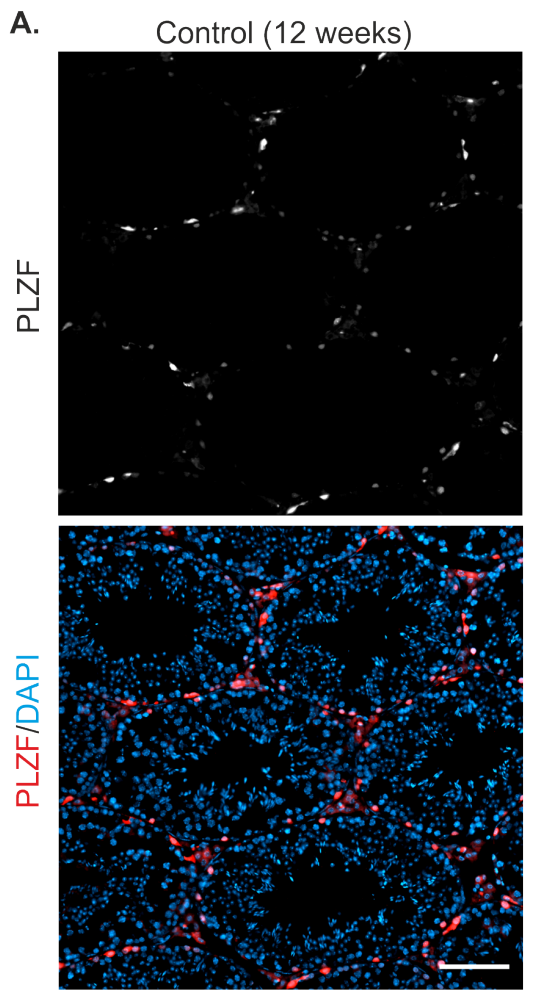

B.



$U_{s f 1^{-1}}(12$ weeks $)$
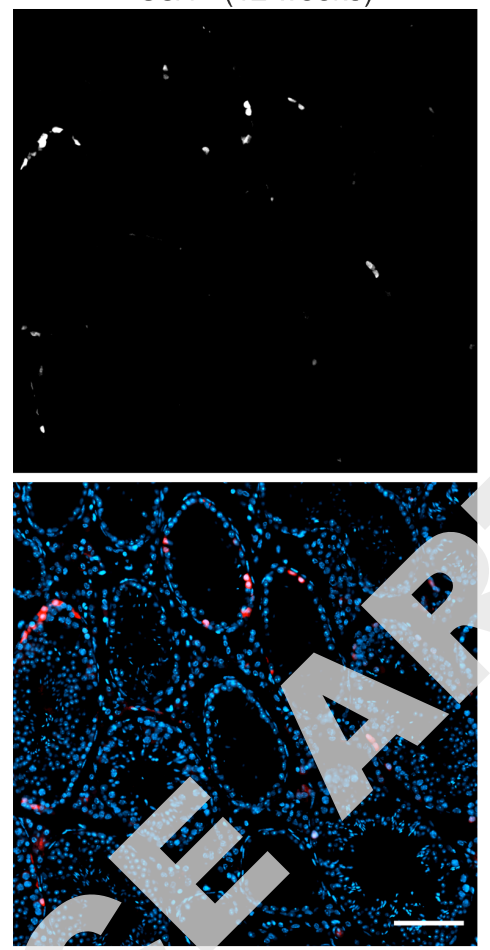

C.

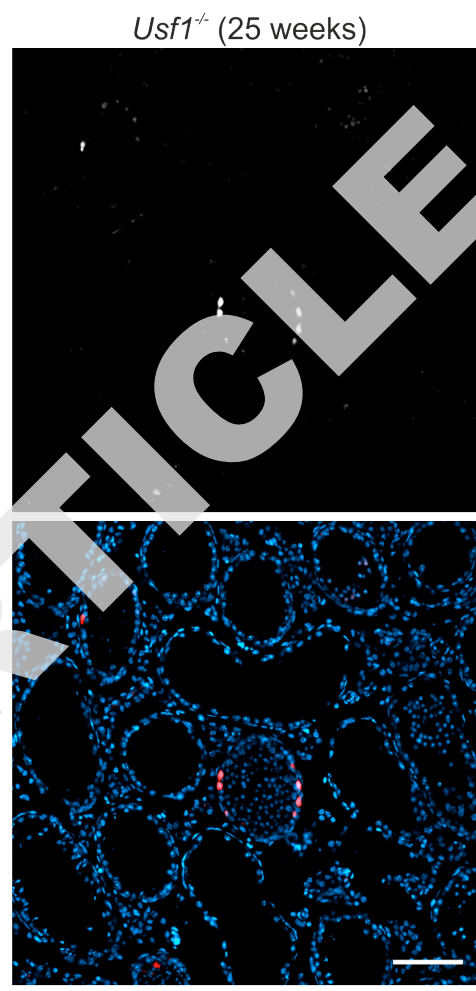

D.
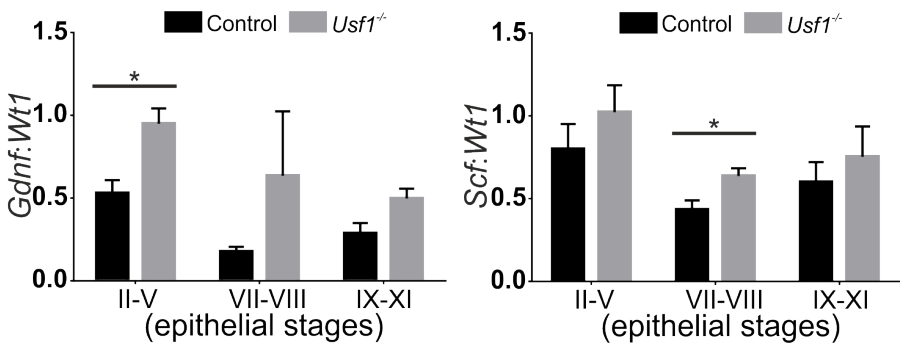

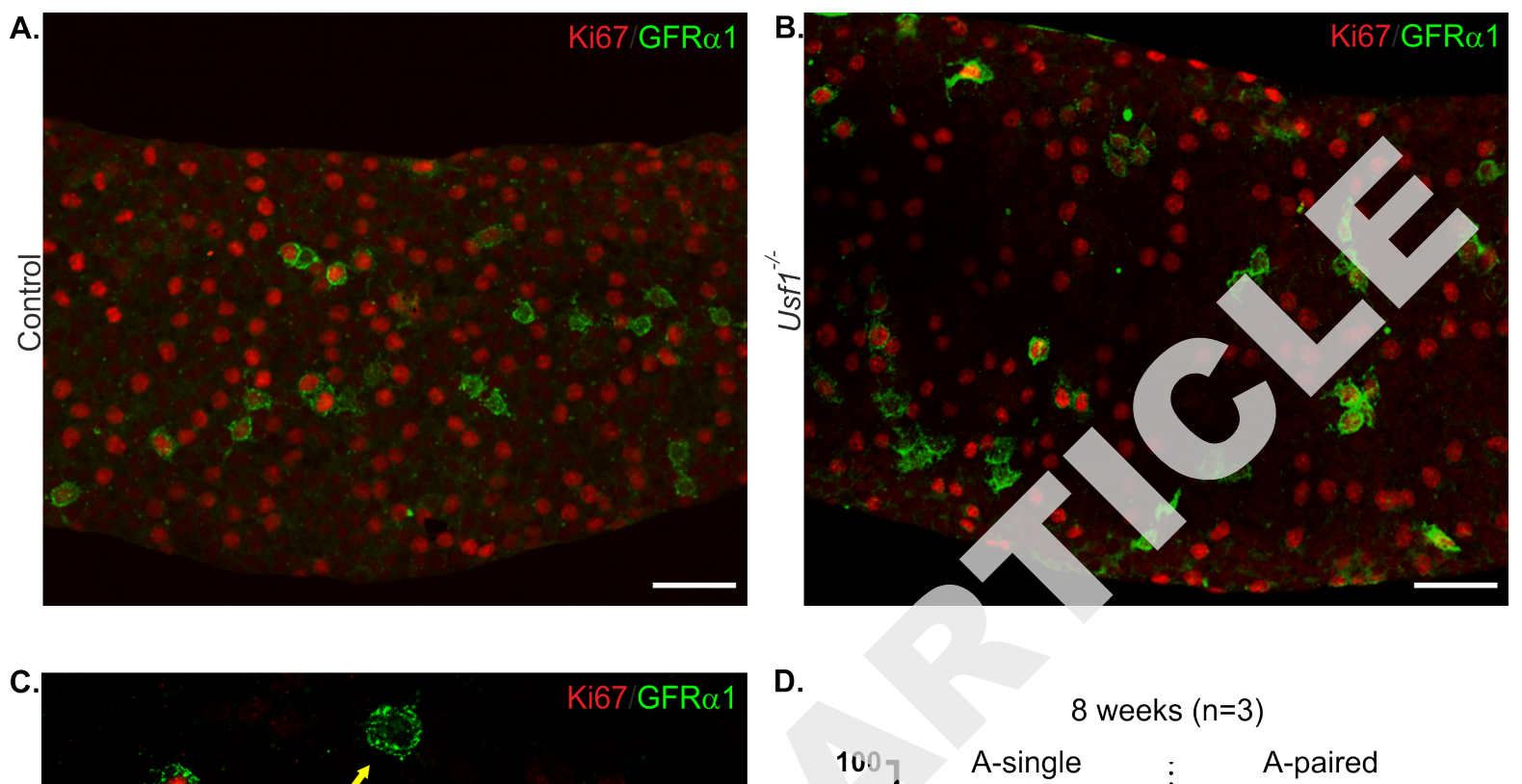

D.

8 weeks $(n=3)$

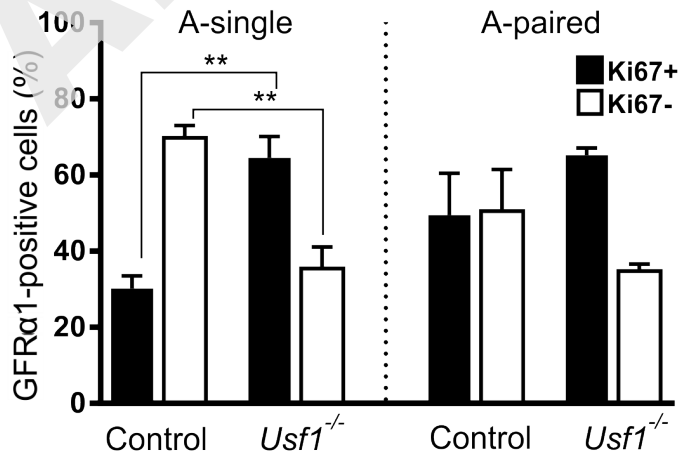




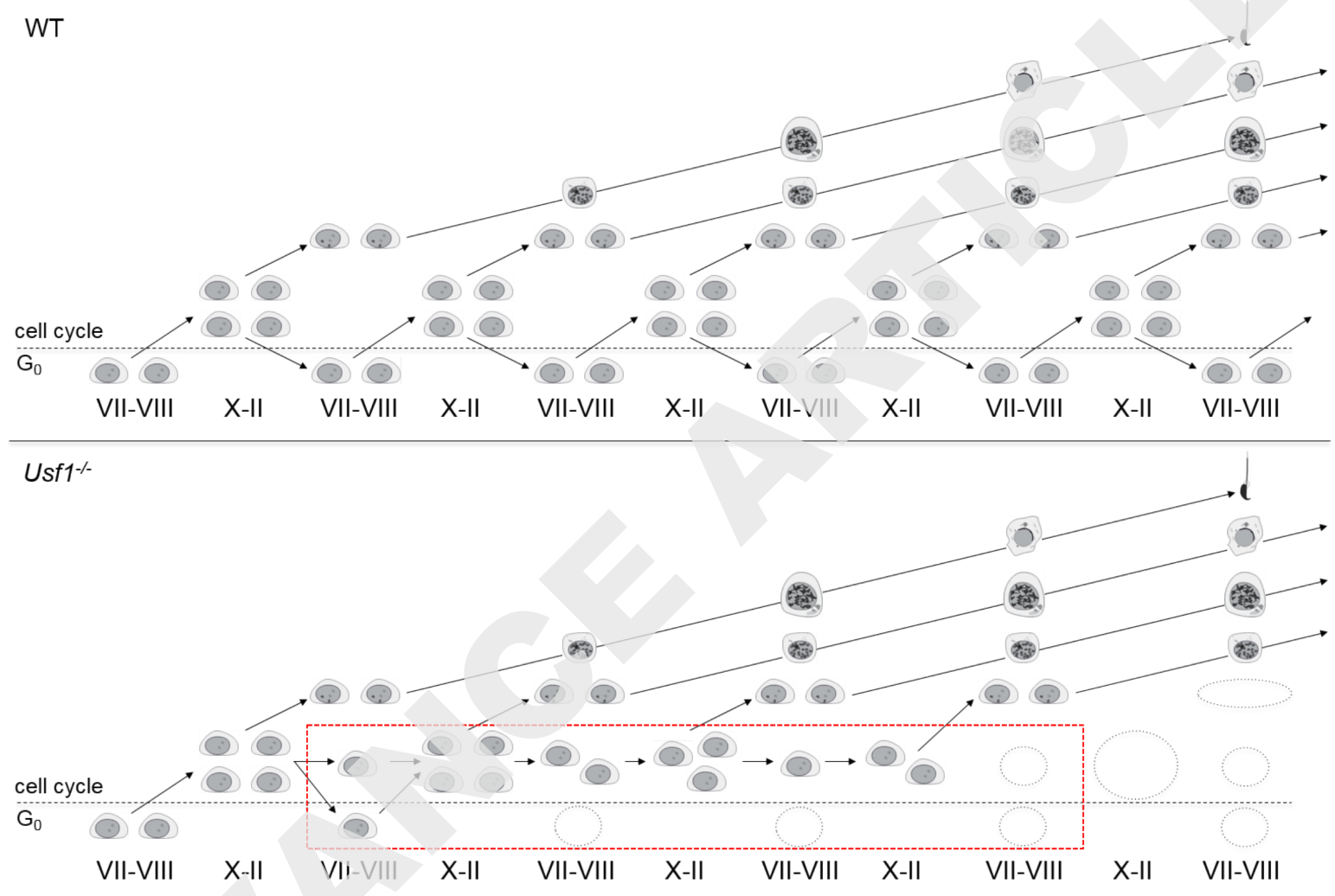

